\title{
Alternative splicing of hepatitis B virus: A novel virus/host interaction altering liver immunity
}

\section{Graphical abstract}

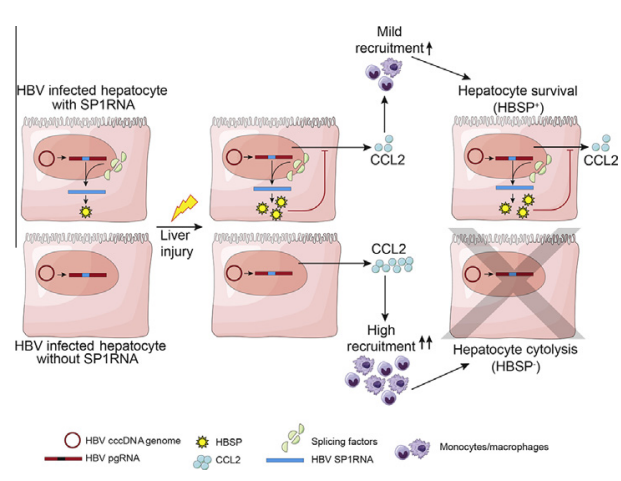

Highlights

- Liver injuries disrupt alternate splicing machinery and increase HBV splicing events.

- Liver immune recruitment is reduced in the presence of HBSP, an HBV splice-protein.

- CCL2 produced by hepatocytes contributes to monocyte/macrophage recruitment.

- CCL2 decrease by HBSP might promote HBV immune escape during liver pathogenesis.

\section{Authors}

Marion Duriez, Yassmina Mandouri, Bouchra Lekbaby, ..., Mala K. Maini, Dina Kremsdorf, Patrick Soussan

\section{Correspondence}

patrick.soussan@inserm.fr

(P. Soussan)

\section{Lay summary}

Hepatitis B virus persists for decades in the liver of chronically infected patients. Immune escape is one of the main mechanisms developed by this virus to survive. Our study highlights how the crosstalk between virus and liver infected cells may contribute to this immune escape. 


\title{
Alternative splicing of hepatitis B virus: A novel virus/host interaction altering liver immunity
}

\author{
Marion Duriez ${ }^{1,2, \dagger}$, Yassmina Mandouri ${ }^{1,2,3, \dagger}$, Bouchra Lekbaby ${ }^{1,2}$, Hualin Wang $^{1,2}$, \\ Aurélie Schnuriger ${ }^{1,2,4}$, Francois Redelsperger ${ }^{1,2}$, Chiara Ida Guerrera ${ }^{5}$, Marine Lefevre ${ }^{6}$, \\ Veronique Fauveau $^{2,5}$, James Ahodantin ${ }^{1,2}$, Ivan Quetier ${ }^{1,2}$, Cerina Chhuon ${ }^{5}$, Samir Gourari ${ }^{7}$, \\ Alexandre Boissonnas ${ }^{1,2}$, Upkar Gill ${ }^{8,9}$, Patrick Kennedy ${ }^{8,9}$, Nabil Debzi ${ }^{10}$, Delphine Sitterlin ${ }^{3,11}$, \\ Mala K. Maini ${ }^{8}$, Dina Kremsdorf ${ }^{1,2}$, Patrick Soussan ${ }^{1,2,12, *}$ \\ ${ }^{1}$ INSERM U1135, Centre d'immunologie et de maladie infectieuse, Paris, France; ${ }^{2}$ Université Pierre et Marie Curie, Paris, France; ${ }^{3}$ Université \\ Versailles Saint Quentin en Yvelines, Versailles, France; ${ }^{4}$ Service de Virologie, Hôpital Trousseau, Paris, France; ${ }^{5}$ Université Paris Descartes, \\ Paris, France; ${ }^{6}$ Service d'Anatomopathologie, Hôpital Tenon, Paris, France; ${ }^{7}$ Service de microbiologie CHU Mustapha Bacha, Alger, \\ Algeria; ${ }^{8}$ Division of Infection and Immunity, UCL, London, UK; ${ }^{9}$ Centre for Immunobiology, Blizard Institute, Barts and The London School of \\ Medicine E Dentistry, QMUL, London, UK; ${ }^{10}$ Service d'Hépatologie, CHU Mustapha Bacha, Alger, Algeria; ${ }^{11}$ Laboratoire de Génétique et \\ Biologie Cellulaire, EA 4589/EPHE, Montigny le Bretonneux, France; ${ }^{12}$ Service de Virologie, Hôpital Tenon, Paris, France
}

Background \& Aims: Hepatitis B virus (HBV) RNA can undergo alternative splicing, but the relevance of this posttranscriptional regulation remains elusive. The mechanism of HBV alternative splicing regulation and its impact on liver pathogenesis were investigated.

Methods: HBV RNA-interacting proteins were identified by RNA pull-down, combined with mass spectrometry analysis. HBV splicing regulation was investigated in chemically and surgically induced liver damage, in whole HBV genome transgenic mice and in hepatoma cells. Viral and endogenous gene expression were quantified by quantitative reverse transcription polymerase chain reaction, Western blot and enzyme-linked immunosorbent assay. Resident liver immune cells were studied by fluorescenceactivated cell sorting.

Results: HBV pregenomic RNA-interacting proteins were identified and $15 \%$ were directly related to the splicing machinery. Expression of these splicing factors was modulated in HBV transgenic mice with liver injuries and contributed to an increase of the HBV spliced RNA encoding for HBV splicing-generated protein (HBSP). HBSP transgenic mice with chemically induced liver fibrosis exhibited attenuated hepatic damage. The protective effect of HBSP resulted from a decrease of inflammatory monocyte/macrophage recruitment through downregulation of $\mathrm{C}-\mathrm{C}$ motif chemokine ligand 2 (CCL2) expression in hepatocytes. In human hepatoma cells, the ability of HBSP to control CCL2 expression was confirmed and maintained in a whole HBV context. Finally, viral spliced RNA detection related to a decrease of CCL2 expression in the livers of HBV chronic carriers underscored this mechanism.

Keywords: HBV; Liver fibrosis; HBSP; Alternate splicing; Macrophages; CCL2. Received 10 July 2016; received in revised form 24 May 2017; accepted 30 May 2017 * Corresponding author. Address: INSERM U1135 CIMI, 91 boulevard de l'Hôpital, 75013 Paris, France. Tel.:+33 140779898; fax: +33 145838858.

E-mail address: patrick.soussan@inserm.fr (P. Soussan).

${ }^{\dagger} \mathrm{MD}$ and YM were co-first authors making an equal contribution.
Conclusion: The microenvironment, modified by liver injury, increased HBSP RNA expression through splicing factor regulation, which in turn controlled hepatocyte chemokine synthesis. This feedback mechanism provides a novel insight into liver immunopathogenesis during HBV infection.

(c) 2017 European Association for the Study of the Liver. Published by Elsevier B.V. All rights reserved.

\section{Introduction}

Constitutive splicing is an essential step for eukaryotic gene expression, generating mature mRNAs by removing introns and allowing exons to be joined together accurately. In contrast, alternate splicing (including exon skipping, intron retention, alternate $3^{\prime}$ or $5^{\prime}$ splice sites) contributes to the diversity of the eukaryotic proteome ${ }^{1}$ and controls the expression of regulatory proteins in the viral context. ${ }^{2}$ The splicing process is coordinated by the spliceosome, a large ribonucleoprotein complex. The process occurs on specific RNA domains, in association with ubiquitous trans-regulatory splicing factors, including serine-arginine-rich (SR) and heterogeneous nuclear ribonucleoprotein (hnRNPs) families. ${ }^{3}$

The ability of Hepatitis B Virus (HBV) transcripts to undergo alternate splicing (AS) has been well described in vitro and in the liver of patients with chronic hepatitis B infection $(\mathrm{CHB}){ }^{4,5}$ The $3.5 \mathrm{~kb}$ pregenomic RNA (pgRNA) of HBV, which encodes capsid and polymerase proteins, and constitutes the template for viral genome replication, can be alternatively spliced. ${ }^{6}$ The major pgRNA spliced variant, SP1RNA, has one third of the viral genome deleted ("intron $2447 / 489$ ") and may account for up to $30 \%$ of total HBV pgRNA. SP1RNA can be packaged in core particles, reverse-transcribed and secreted. While pgRNA packaging leads to wild-type Dane particle secretion (wtHBV), the shorter 


\section{Research Article}

SP1RNA constitutes a matrix for defective HBV circulating particles (dHBV), varying in proportion from $0 \%$ to more than $50 \%$ of HBV forms. ${ }^{7-10}$ The regulation of SP1RNA during liver disease remains poorly understood. However, recent reports in HBV infected patients have shown that the proportion of $\mathrm{dHBV}$ relates to viral replication, to interferon therapy failure ${ }^{11}$ and increases with liver disease progression towards hepatocellular carcinoma (HCC). 8,9

SP1RNA allows HBV splicing-generated protein (HBSP) to be expressed. HBSP shares the 46 amino-acid N-terminal sequence of the viral polymerase fused to an original 65 amino-acid viral sequence, which constitutes the C-terminus. HBSP has been identified in liver tissues from patients with $\mathrm{CHB},{ }^{12}$ in whom it can induce an immune response. ${ }^{13}$ The function of HBSP in liver pathogenesis remains uncertain, although in vitro studies have suggested that it impacts on cell viability, proliferation and migration, ${ }^{12,14}$ and more recently that it is involved in hacking the TNF- $\alpha$ signaling pathway. ${ }^{15}$

The previous observation that dHBV particles increase with liver disease progression prompted us to investigate whether, and how, regulation of HBV AS and liver pathogenesis are mechanistically linked. Because of the lack of robust animal models of liver pathogenesis induced by HBV infection, we decided to investigate the viral post-transcriptional regulation in HBV transgenic mice. ${ }^{16}$ We report that alteration of spliceosome machinery in HBV expressing cells is switched on by liver injury and enables a striking reduction in liver monocyte/macrophage recruitment through HBSP expression. Our findings reveal a novel paradigm whereby AS can generate a viral product able to inhibit immune-mediated inflammation and thereby down-modulate organ damage.

\section{Materials and methods}

Mice and liver pathogenesis models

Inbred C57BL/6J HBV-transgenic mouse lineage 1.3.32 (TgHBV) has been described previously. ${ }^{17}$ TgHBV mice express and replicate HBV in the liver under the control of HBc promoter/enhancer-II. The two-independent transgenic HBSP1 and HBSP2 mice strains carry HBSP gene (333 bp) encoding for the HBSP protein under the control of the HBx promoter/enhancer I (nt 832/1371). ${ }^{15} \mathrm{~A}$ rabbit $\beta$ globin intron was inserted between the HBx promoter/enhancer-I sequence and HBSP gene (genotype A). HBSP1 and HBSP2 transgenic mice were generated and expanded by back-crossing against the C57BL/6J strain ( $>12$ backcrossings). C57BL/6J invalidated for CCR2 gene expression (CCR2 ${ }^{-1-}$ ) mice were also used. ${ }^{18}$ All experiments were performed on two-month old, heterozygous TgHBV, TgHBSP1, TgHBSP2 or homozygous $C C R 2^{-1-}$ and corresponding littermate (WT) male mice.

WT and TgHBV mice were treated for seven weeks with carbon tetrachloride intraperitoneal injections $\left(\mathrm{CCl}_{4}, 1 \mathrm{ml} / \mathrm{kg}\right.$ in oil, Sigma) twice a week to induce chronic liver fibrosis. Fulminant liver injury was generated by surgical bile duct ligation (BDL) using double sutures of bile duct near liver junctions; WT and TgHBV mice were monitored for two days before sacrifice. Lipopolysaccharide intraperitoneal injections (LPS, $2.5 \mathrm{mg} / \mathrm{kg}$, Sigma) were performed on WT and TgHBV mice three times a week for two weeks to induce liver inflammation. TgHBSP, CCR2 ${ }^{-1-}$ and corresponding WT mice were treated twice a week with $\mathrm{CCl}_{4}(1 \mathrm{ml} / \mathrm{kg}$ in oil, Sigma) for two and/or 10 weeks. Acute liver injury was also performed in TgHBSP1 mice by a single intraperitoneal injection of $\mathrm{CCl}_{4}$ $(1 \mathrm{ml} / \mathrm{kg}$ in oil). Thioacetamide intraperitoneal injections (TAA, $250 \mathrm{mg} / \mathrm{kg}$ in PBS, Sigma) three times a week were performed on WT and TgHBSP1 mice for two weeks to induce liver fibrosis. TgHBV, TgHBSP and littermate WT were sacrificed 48 to $72 \mathrm{~h}$ after the last injection. Mice livers were perfused with PBS-2\% FCS and removed for analysis. Animals were maintained in pathogen-free conditions on $12 \mathrm{~h}$ dark/light cycles and treated in accordance with EU regulations on animal care (Directive 86/609/EEC). All procedures were approved by the local animal care and use committee (Agreement A75-14-08; $\mathrm{n}^{\circ} 02890$ and 02891). Alanine aminotransferase (ALT) in serum was measured on a Cobas ${ }^{\circledR}$ 6000 analyzer (Roche), according to the manufacturer's instructions.

Human HBV infected liver samples

Patients were recruited from Mustapha Hospital (Alger, Algeria) and The Royal London Hospital (London, UK). Full ethical approval was obtained for the study; agreements by the National Health Ministry (according to legal article about clinical trials $n^{\circ} 387$ et 388 of 31/07/2006) and the Local Ethical Review Board at the Royal London Hospital. All patients recruited gave written informed consent. Liver samples, from biopsies surplus to diagnostic requirements, were obtained from 12 HBV-mono-infected patients. Patients were anti-HCV, anti-HDV and anti-HIV antibody negative and treatment naive. All patients had evidence of moderate liver damage; scored by a pathologist according to the Metavir stage. ALT, HBeAg and HBsAg titres were determined using commercial assays (Roche, Biorad and Diasorin, respectively).

For further details regarding the materials used, please refer to the Supplementary material and the CTAT table.

\section{Results}

Increase in HBV alternate splicing upon liver injury

To assess whether liver injury impacts on HBV splicing regulation, TgHBV were treated with either $\mathrm{CCl}_{4}$ (seven weeks/IP) or LPS (two weeks/IP) to induce liver fibrosis or inflammation, respectively (Figs. S1 and S2). The amount of HBV pgRNA was reduced 5.3-fold and a 3.9-fold in LPS and $\mathrm{CCl}_{4}$ treated TgHBV mice, respectively (Fig. $1 \mathrm{~A}$ ). LPS and $\mathrm{CCl}_{4}$ also reduced $\mathrm{HBV}$ viral load (Fig. S3). In contrast, HBV AS was significantly increased (Fig. 1A). Indeed, quantification of HBV pgRNA and SP1RNAderived forms showed a significant increase in the SP1RNA proportion in both $\mathrm{CCl}_{4}$ and LPS-treated TgHBV mice compared to control mice (oil-TgHBV vs. $\mathrm{CCl}_{4}$-TgHBV: $32.5 \pm 9.6 \%$ vs. $49.7 \pm 17.2 \%, p=0.04$; PBS-TgHBV vs. LPS-TgHBV: $27.6 \pm 8.7 \%$ vs. $42.7 \pm 10.1 \%, p=0.01$ ). Additionally, HBV AS upregulation was also observed in TgHBV mice with a BDL-induced fulminant hepatitis (control-TgHBV vs. BDL-TgHBV: $30.6 \pm 4.9 \%$ vs. $69.0 \pm 3.0 \%$, $p=0.001$ ) (Fig. S4). These results provide support for liver damage influencing HBV post-transcriptional regulation.

Previous clinical studies suggested a correlation between HBV alternative splicing and the course of liver disease, ${ }^{8,9}$ but the relevance of HBV pgRNA splicing to liver pathogenesis remained unknown. We therefore compared liver fibrosis or inflammation following $\mathrm{CCl}_{4}$ or LPS treatment of TgHBV and their littermate wild-type (WT) control mice. Despite the well-known activities of HBV proteins on signaling pathways involved in inflammatory and fibrotic processes, ${ }^{19} \mathrm{CCl}_{4}$-treated TgHBV and WT mice displayed a comparable low stage of liver fibrosis (F2) on histological section (Fig. 1B). This was confirmed by quantification of collagen deposition and the expression of genes involved in liver fibrosis. Similarly, liver histology, staining for CD45+ cells and quantification of inflammation-inducible genes confirmed an equivalent degree of liver injury in LPS-treated WT and TgHBV mice (Fig. 1C and Fig. S5).

Since several viral proteins may have an impact on liver disease, it was difficult to define the role of HBV AS and related HBSP expression in this experimental model. However, the lack of increase in $\mathrm{CCl}_{4}$-induced liver injury in TgHBV mice, expressing the complete HBV genome, contrasted with the exacerbations 


\section{JOURNAL OF HEPATOLOGY}
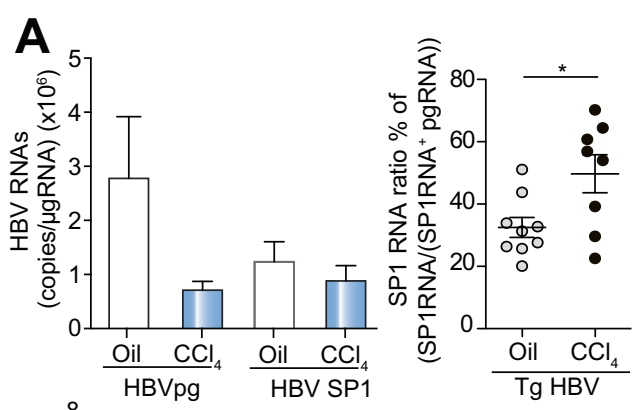

B
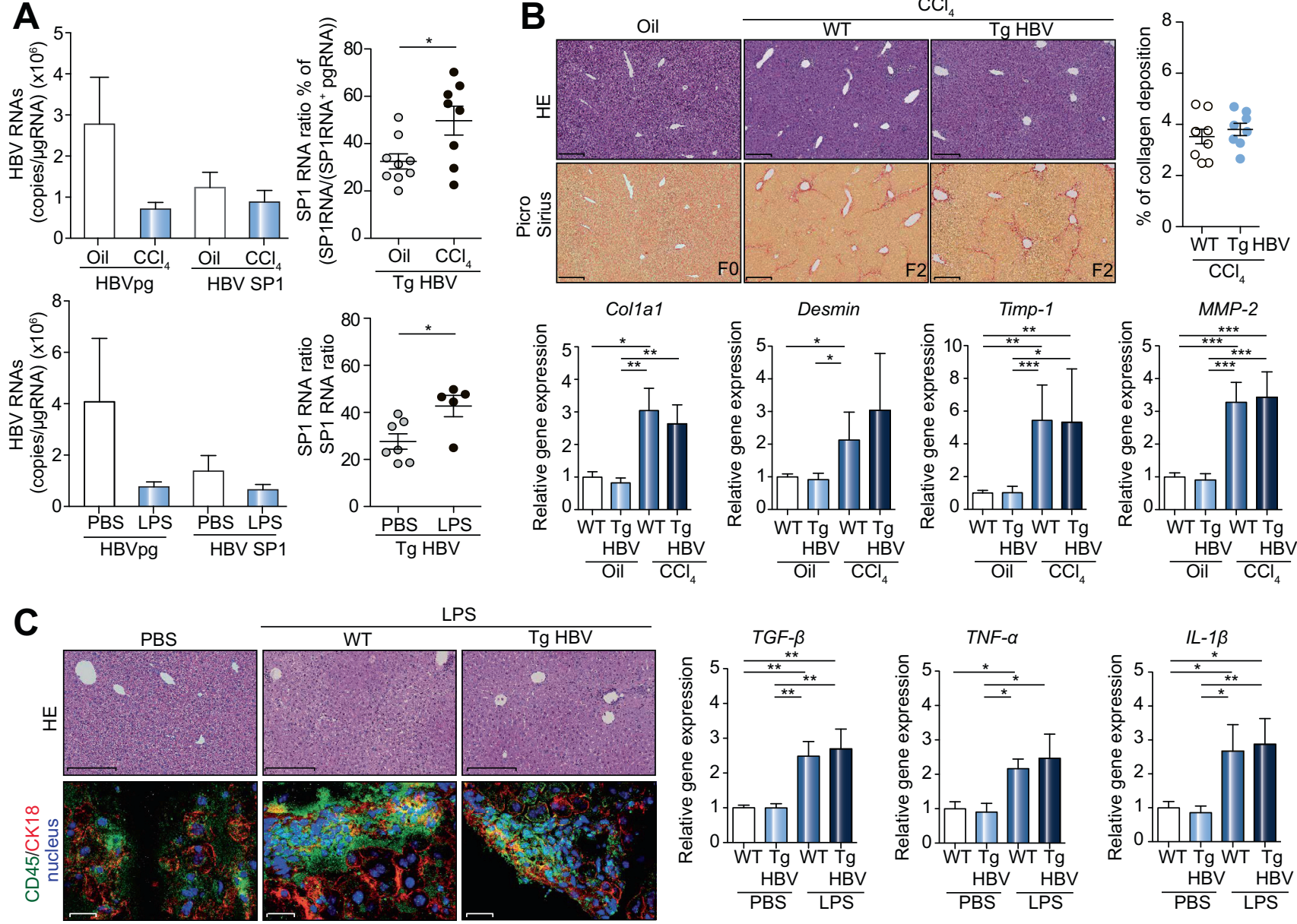

Fig. 1. Liver injury increases HBV pgRNA alternate splicing in HBV transgenic mice. (A) HBV pgRNA and SP1RNA expression (left) and SP1RNA proportion (right) quantified in the liver of TgHBV mice treated with oil/CCl 4 for seven weeks or with PBS/LPS for two weeks. (B) Representative H\&E and Picro-Sirius red stained histological liver section (left, bar $250 \mu \mathrm{m}$ ) and quantification of collagen deposition (right) from seven weeks oil, $\mathrm{CCl}_{4}$-WT and $\mathrm{CCl}_{4}$-TgHBV treated mice (upper panel). Fibrosis-related mRNA expression in the liver, each dot represents a mouse, experiments were performed on oil-WT $(n=7)$, oil- $\mathrm{TgHBV}(\mathrm{n}=7), \mathrm{CCl}{ }_{4}-\mathrm{WT}(\mathrm{n}=9)$ and $\mathrm{CCl}{ }_{4}-\mathrm{TgHBV}(\mathrm{n}=8)$ mice (lower panel). C) Representative H\&E histological staining (upper, bar: $250 \mu \mathrm{m}$ ); CD45 and Cytokeratin 18 (CK18) immunofluorescence staining on liver section (lower, bar: $50 \mu \mathrm{m}$ ) from two weeks PBS, LPS-WT and LPS-TgHBV treated mice (upper panel). Cytokines mRNA expression in the liver of 2 weeks PBS or LPS-treated WT and TgHBV mice. Each dot represents a mouse; experiments were performed on PBS-WT ( $n=6)$, PBS-TgHBV ( $n=7)$, LPS-WT ( $n=5)$, and LPS-TgHBV ( $n=5)$ treated-mice (lower panel). Mann-Withney U-tests: ${ }^{*} p<0.05,{ }^{* *} p<0.01$ and ${ }^{* * *} p<0.001$.

previously observed in transgenic mice expressing a subgenomic HBV sequence that is unable to express SP1RNA. ${ }^{20}$ Considering the high level of SP1RNA in the liver of TgHBV mice, we hypothesized that HBV AS, triggered by liver injury could limit the ensuing liver inflammation and fibrosis. To understand the role of SP1RNA during liver pathogenesis, we first investigated its regulation.

\section{Identification of HBV alternate splicing factors}

Characterization of pgRNA trans-regulatory splicing proteins remained a crucial prerequisite for investigations into HBV AS regulation. Thus, HepG2 nuclear proteins interacting with HBV pgRNA were explored by RNA pull-down assay. Identification and relative quantification by Orbitrap mass-spectrometry, in six independent experiments, showed that 389 proteins were significantly associated with viral pgRNA (Fig. 2A and Table S1).
Classification by gene ontology according to the biological functions allowed creation of five distinct groups, representing $88 \%$ of associated-proteins (12\% of proteins remained classified in group "other") (Fig. 2B). The most significant group was the "RNA processing" family, which was mainly composed of factors directly involved in RNA splicing (28/68 proteins; stained in Fig. 2C). Moreover, 30 additional proteins involved in RNA splicing and comprising hnRNPs proteins, were classified into additional groups (Table S1). As illustrated, the proteins belonging to the "RNA processing" group have additional biological functions, which may contribute to the liver disease progression during infectious disease. Specific interactions of nine transregulatory splicing factors, hnRNPAB, SF1, La, PSF and SRSF1, 4, $5,6,7$ were confirmed in the pgRNA pull-down extract and not in controls (using antisense HBV pgRNA and empty beads) by Western blot (Fig. 2D). The splicing factors SRSF2 and hnRNPH, absent or not significantly linked to pgRNA, were used as controls. 


\section{Research Article}

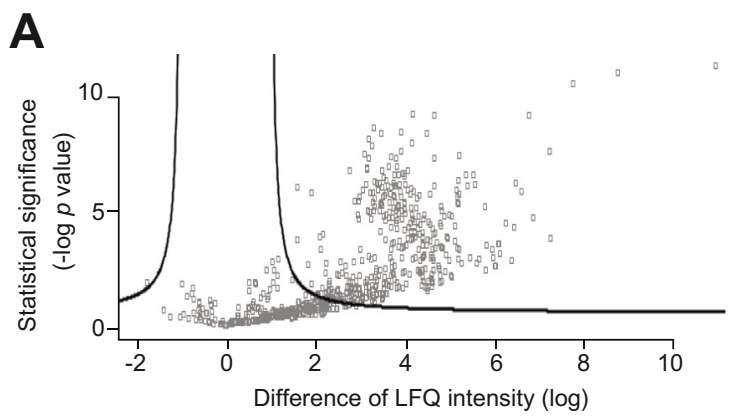

\section{B}

\begin{tabular}{lrcc}
\hline $\begin{array}{l}\text { Protein } \\
\text { function }\end{array}$ & \multicolumn{2}{c}{$p$ value } & pumber of \\
\hline RNA processing & $3.9 \times 10^{-4}$ & $4.3 \times 10^{-53}$ & protein \\
\hline Protein synthesis & $3.2 \times 10^{-6}$ & $1.1 \times 10^{-17}$ & 68 \\
Cancer & $4.9 \times 10^{-1}$ & $1.4 \times 10^{-17}$ & 315 \\
Organismal injury & $1 \times 10^{-0}$ & $1.4 \times 10^{-17}$ & 326 \\
Infectious disease & $5.7 \times 10^{-4}$ & $2.6 \times 10^{-13}$ & 86 \\
\hline
\end{tabular}

C

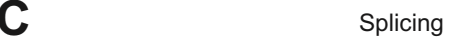

$+$

-

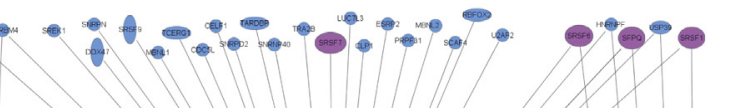

RNA processing

D

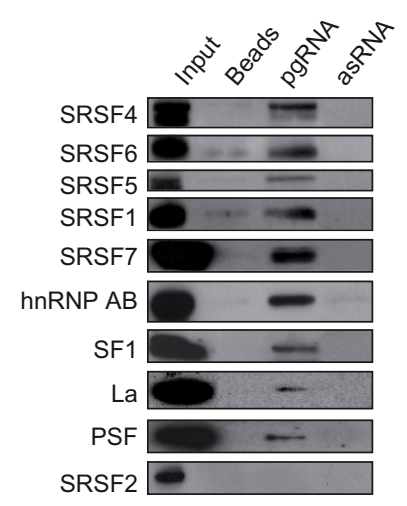

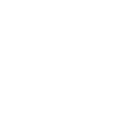

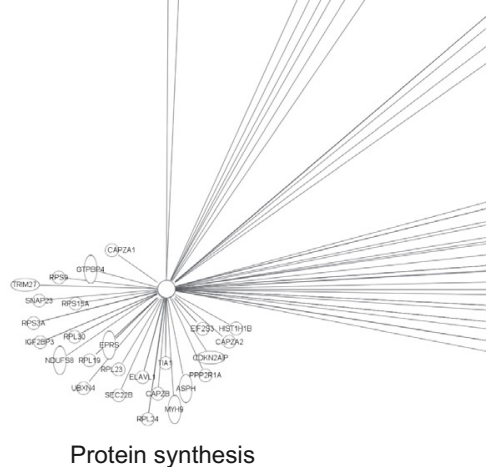

Protein synthesis

Fig. 2. Identification of cellular splicing factors interacting with HBV pgRNA. (A) Volcano plot representation of HBV pgRNA-interacting proteins (700/1442) detected in six independent RNA pull-down assays (beads used as control) and identified by mass spectrometry (nanoRSLC-LTQ Orbitrap Velos). Proteins showing a significant interaction with HBV pgRNA $(n=389 / 700)$ are depicted uppers the black line according to significance analysis. X-axis shows the difference of the average of the logarithm of Label Free Quantification (LQF) intensities between pgRNA and control; y-axis shows the negative logarithmic of t-test Welsh p-value. (B) Biological function groups of HBV pgRNA binding proteins identified. (C) Schematic network presenting the main protein families binding to HBV pgRNA according to Ingenuity software. Transregulatory splicing factors are colored in blue and the ones selected for further characterization are colored in pink. (D) HBV pgRNA pull-down extract analysis by Western blot confirming a specific interaction of nine selected trans-regulatory splicing factors with pgRNA (antisense pgRNA (asRNA), beads and SRSF2 protein were used as negative control).

Splicing proteins are implicated in the regulation of $\mathrm{HBV}$ alternate splicing

The modulation of expression of HBV pgRNA interacting transregulatory splicing proteins (conserved inter-species) was investigated in liver extracts of TgHBV mice. Chemical induction of fibrosis led to an overexpression of PSF and SF1 proteins, whilst LPS-induced liver inflammation increased the expression of SRSF1 and La proteins (Fig. 3A). Despite the differential signature of splicing factor expression in both liver disease models, a comparable increase of SP1RNA proportion was observed. It was considered that AS regulation in eukaryotic cells has largely been driven by the alteration of cis-regulatory elements. These data provide additional evidence suggesting AS regulation and transregulatory protein expression relate to liver damage. ${ }^{21}$

Conservation of splicing factors in mammals led us to investigate their involvement on HBV AS in vitro. Once different human hepatoma cells were tested, impact of PSF, SRSF1 and La expression in viral AS regulation was investigated (Fig. 3 B-D). In Huh7 expressing HBV cells, La and PSF proteins increased SP1RNA proportion, whereas SRSF1 led to a decrease in viral splicing efficiency (Fig. 3E). This paradoxical decrease may be attributable to the fact that SRSF1 expression also considerably reduced HBV transcription, core and HBeAg expression (Fig. 3D), suggesting an impact on HBV RNA synthesis or metabolism. Taken together, these data emphasised the possible influence of the microenvironment, altered by liver injury, on the expression of the HBV-regulatory splicing factors we had defined, driving regulation of the SP1RNA and consequently HBSP expression.

\section{HBSP protein partially prevents $\mathrm{CCl}_{4}$-induced liver fibrosis}

The impact of the HBV alternative splicing product HBSP on liver pathology was investigated in two transgenic mouse strains 


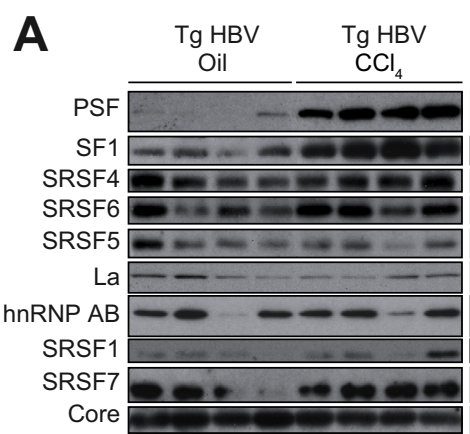

SRSF2

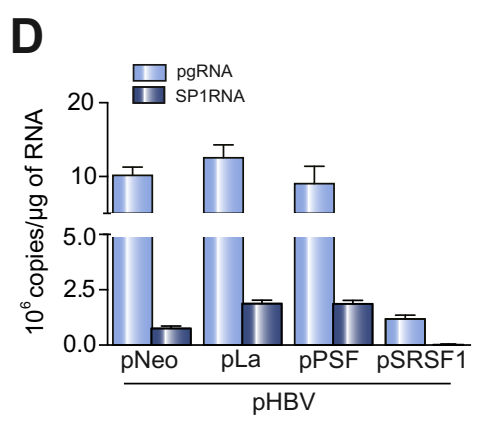

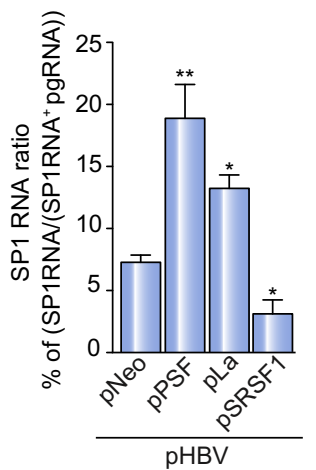

B

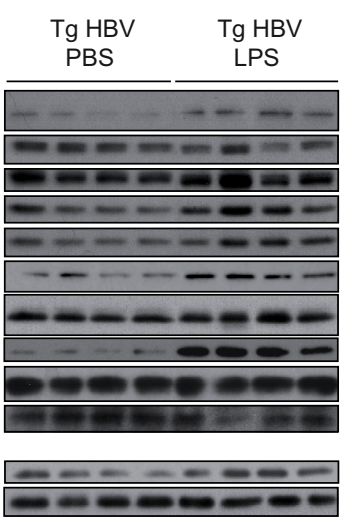

pHBV
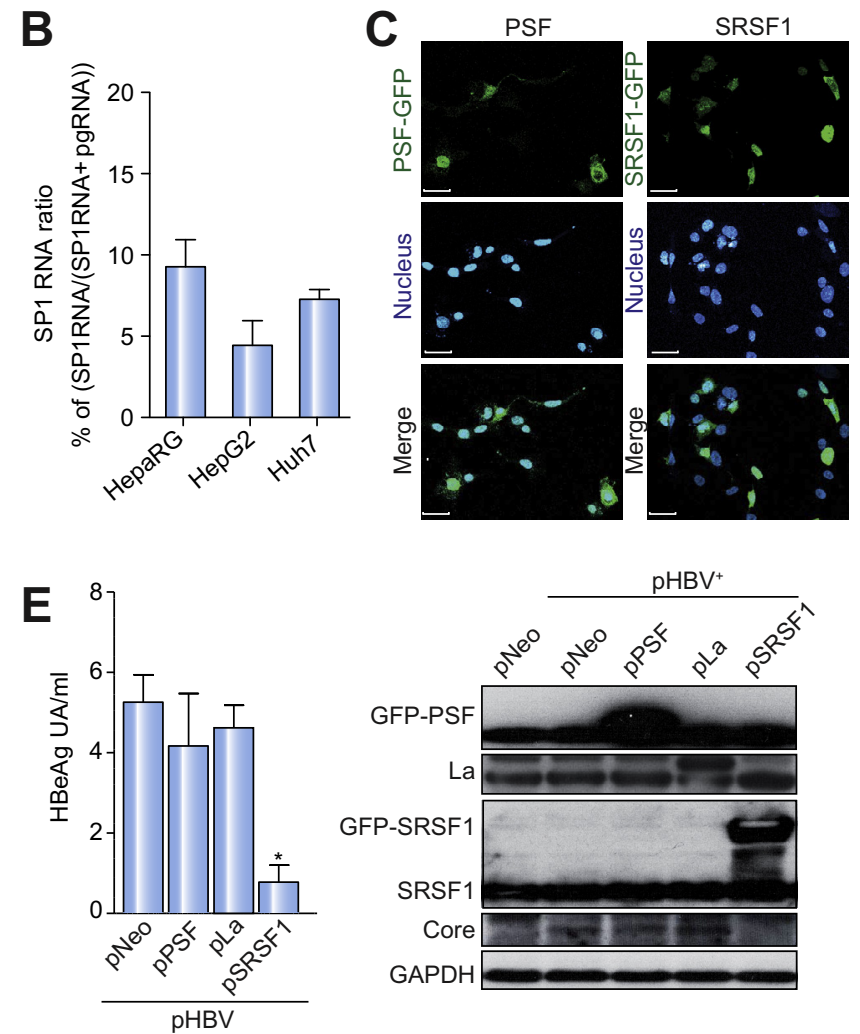

Fig. 3. SP1RNA regulation is dependent on splicing-proteins expression. (A) Splicing regulatory proteins expression in the liver of TgHBV mice treated with oil/CCl for seven weeks or with PBS/LPS for two weeks (SRSF2 and hnRNPH1 used as controls). (B) SP1RNA proportion (SP1RNA/(SP1RNA + pgRNA) $\times 100)$ in Huh7, HepG2 and HepaRG cells expressing HBV after transient transfection of pHBV vector. (C) Huh7 co-tranfected cells with pHBV and PSF-GFP or SRSF1-GFP; PSF-GFP and SRSF1-GFP visualization and nucleus were counter stained with Hoescht (middle, bar $50 \mu \mathrm{m}$ ); (D) pgRNA and SP1RNA quantification in HBV expressing Huh7 cells co-transfected with Neo (control), PSF, La or SRSF1 plasmids (left panel), and (right panel) HBV SP1RNA proportion in these cells ( $\mathrm{n} \geq 3$ experiments). (E) HBeAg cell supernatant quantification (left panel) and PSF, SRSF1, La and Core expression by Western blot (right panel). Mann-Withney U-tests: ${ }^{*} p<0.05,{ }^{* *} p<0.01$ and ${ }^{* * *} p<0.001$.

TgHBSP1 and TgHBSP2 expressing the HBSP gene under the control of the weak hepato-specific HBx promoter (Fig. S6). The amount of HBSP RNA in TgHBSP mice was up to 10-fold less than SP1RNA expression in TgHBV mice $\left(1.2 \times 10^{5} \pm 3.4 \times 10^{4}\right.$ vs. $1.2 \times 10^{6} \pm 9.9 \times 10^{5}$ copies/ $\mu$ g of liver RNAs, respectively) and remained stable with aging (Fig. S5). ${ }^{15}$ Since TgHBSP mice did not spontaneously develop liver pathogenesis, WT and TgHBSP mice were challenged for two weeks with $\mathrm{CCl}_{4}$ or TAA to induce liver fibrosis (Fig. 4A and B, S6). Surprisingly, and despite a low fibrosis score (F0/F1) for all mice, TgHBSP mice treated with $\mathrm{CCl}_{4}$ or TAA revealed a reduction in collagen deposition compared to their WT littermates.

To evaluate whether HBSP limited the extent of chemicallyinduced fibrogenesis and to investigate its biological impact on advanced stages of liver fibrosis, WT and TgHBSP1 mice were challenged with $\mathrm{CCl}_{4}$ for 10 weeks (Fig. S6). As expected, all WT treated mice displayed severe fibrosis with periportal septa and developed cirrhosis (F4) $(n=8 / 8)$ (Fig. 4C). In contrast, TgHBSP1 treated-mice exhibited less marked fibrosis, with $75 \%$ of animals having an F2 $(\mathrm{n}=2 / 8)$ and F3 $(\mathrm{n}=4 / 8)$ fibrosis score and only $25 \%$ reaching the $\mathrm{F} 4$ cirrhotic state $(n=2 / 8)$. This observation was corroborated by a significant two-fold decrease in collagen deposition in TgHBSP1 liver tissue compared to WT mice upon $\mathrm{CCl}_{4}$ treatment (Fig. 4C; $4.5 \pm 1.2 \%$ vs. $8.4 \pm 1.2 \%, p=0.0002$, respectively). The expression of pivotal fibrosis-related genes Col1a1,
Desmin, Timp-1 and MMP-2 confirmed the lower sensitivity of HBSP mice to 10 weeks $\mathrm{CCl}_{4}$-induced fibrosis (Fig. 4D). In accordance with these results, $\alpha$-SMA protein expressed by activated hepatic stellate cells (HSCs) was detected in greater amounts in the livers of WT compared to TgHBSP1 mice.

Recruitment of immune cells to the liver plays a central role in hepatic fibrogenesis. ${ }^{22}$ To investigate whether this was altered by the expression of HBSP, intrahepatic leucocytes from mice treated with $\mathrm{CCL}_{4}$ for 10 weeks, were isolated and characterized by flow cytometry. The $\mathrm{CCl}_{4}$-induced liver leucocyte infiltrate was significantly decreased in TgHBSP1 compared to WT mice (Fig. 5A). No significant difference in the intrahepatic upregulation of $\mathrm{CD}_{49 \mathrm{~b}^{+}} \mathrm{NK}, \mathrm{CD}^{+}$and $\mathrm{CD}^{+} \mathrm{T}\left( \pm \mathrm{CD} 44^{\mathrm{hi}}\right)$ cells was observed between WT and TgHBSP1 mice treated with $\mathrm{CCl}_{4}$ (Fig. 5B and C). In contrast, the number and proportion of liver monocytes/macrophages, defined as $\mathrm{CD} 45^{+} \mathrm{F} 4 / 80^{+} \mathrm{CD} 11 \mathrm{~b}^{+}$cells, were significantly reduced in TgHBSP1 compared to WT mice treated with $\mathrm{CCl}_{4}$ (Fig. $5 \mathrm{D} ; 2.6 \pm 0.5 \times 10^{5}$ vs. $4.7 \pm 0.5 \times 10^{5}$ cells, $p=0.02$ and $14.5 \pm 2.1 \%$ vs. $21.2 \pm 1.8 \%$ of $\mathrm{CD}^{2} 5^{+}, p=0.02$, respectively) (Fig. 5D). In addition, $\mathrm{CCl}_{4}$-challenged WT mice exhibited a higher periportal infiltrate of $\mathrm{F} 4 / 80+$ monocytes/macrophages than TgHBSP1 treated mice on stained liver sections (Fig. 5E).

Monocytes/macrophages contribute to liver fibrosis through the secretion of inflammatory cytokines, which directly activate HSCs. ${ }^{23}$ In line with this, we confirmed that upon $\mathrm{CCl}_{4}$-induced 


\section{Research Article}
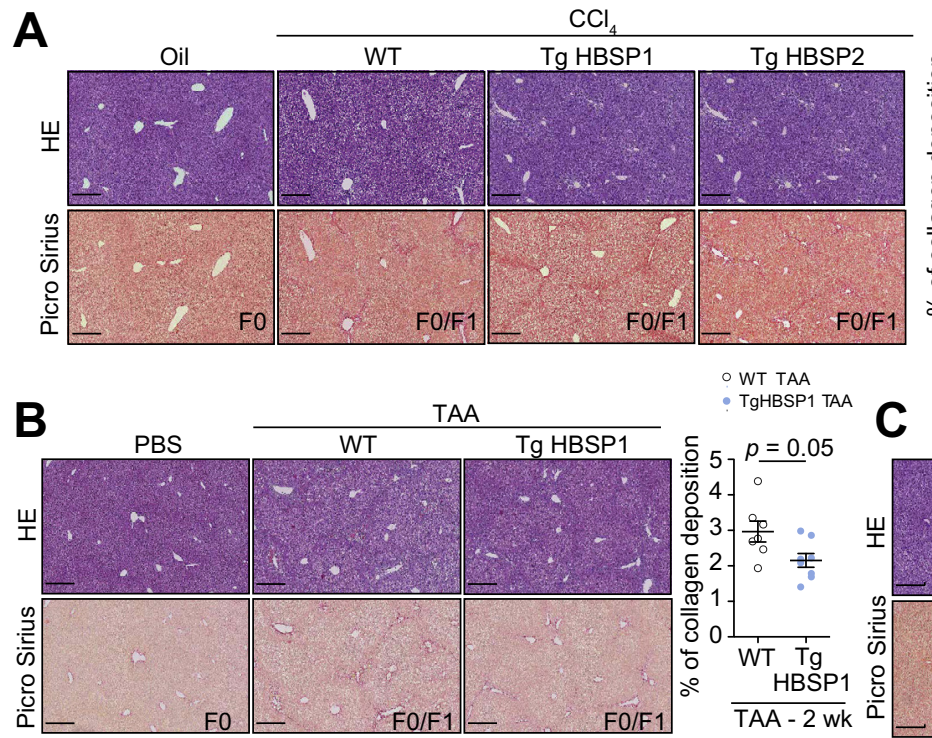
WT TAA
- TgHBSP1 TAA
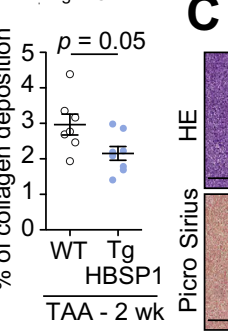
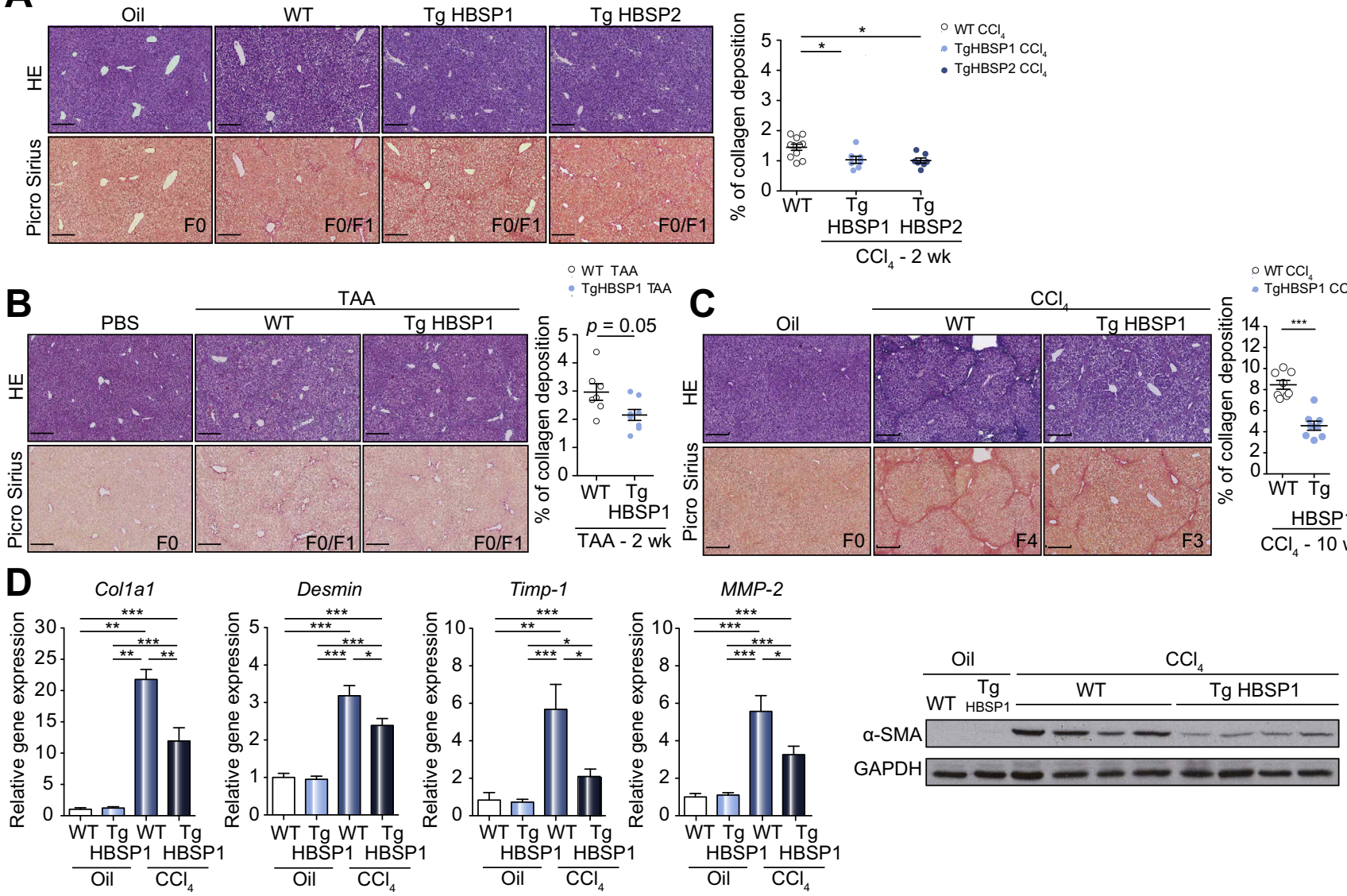

Fig. 4. HBSP expression protects against chemical-induced liver fibrosis. Representative H\&E and Picro-Sirius red stained histological liver section (bar $250 \mu \mathrm{m})$ (left) and quantification of collagen deposition (right) from: (A) WT, TgHBSP1 and TgHBSP2 mice treated for two weeks with Oil $(n=4), C C l_{4}-W_{T}(n=11), C C l_{4}-T_{g H B S P 1}(n=7)$ and $\mathrm{CCl}_{4}$-TgHBSP2 $(\mathrm{n}=7)$ mice. (B) WT and TgHBSP1 mice treated for 2 weeks with PBS $(\mathrm{n}=4$ for both) or TAA-WT $(\mathrm{n}=7)$ and TAA-TgHBSP1 $(\mathrm{n}=8)$ mice. $(\mathrm{C})$ WT and TgHBSP1 mice treated for 10 weeks with oil ( $\mathrm{n}=6$ for both WT and TgHBSP1) or $\mathrm{CCl}_{4}(\mathrm{n}=8$ for both WT and TgHBSP1). (D) Liver fibrosis-related gene mRNA and $\alpha$-SMA protein expression in the liver of WT and TgHBSP1 mice treated for 10 weeks with oil or $\mathrm{CCl}_{4}$. Each dot represents a mouse. Mann-Withney $\mathrm{U}$-tests: ${ }^{*} p<0.05$, ${ }^{* *} p<0.01$ and ${ }^{* * *} p<0.001$

chronic fibrosis, TgHBSP1 mice displayed a less pro-fibrotic inflammatory environment than WT mice, with a significant decrease in TGF- $\beta$, TNF- $\alpha$ and IL-1 $\beta$ gene expression (Fig. 5F), without differential distribution of monocyte/macrophage ontogeny markers CD163 and Marco (Fig. S8). ${ }^{24}$ Next, we investigated the hypothesis that the decrease in monocyte/macrophage infiltrate in the HBSP-expressing liver could result from the impaired production of a chemokine involved in monocyte/macrophage survival and/or recruitment within the liver. ${ }^{25} \mathrm{C}-\mathrm{C}$ motif chemokine ligand $(C C L) 1, C C L 2, C C L 3, C-X-C$ motif chemokine ligand (CXCL)10 and CX3CL1 transcripts were quantified and only CXCL10 and CCL2 were significantly reduced in the liver of TgHBSP1 compared to WT treated mice (Fig. 5F). Together, these results show that HBSP expression partially restricts chronic induced liver fibrosis.

HBSP impairs the monocyte/macrophage recruitment during liver injury

One explanation for the limited liver pathogenesis observed in TgHBSP1 mice could be resistance of HBSP-expressing hepato- cytes to $\mathrm{CCl}_{4}$-induced cytotoxicity. To investigate this possibility, WT and TgHBSP1 mice were treated with a single $\mathrm{CCl}_{4}$-injection to induce acute liver injury. In the context of acute hepatitis, TgHBSP1 and WT mice displayed similar degrees of liver injury, with a similar increase in circulating ALT and equivalent central and periportal necrosis (Fig. 6A). The metabolism of $\mathrm{CCl}_{4}$ in hepatocytes leads to reactive oxygen species (ROS) production and hepatocyte necrosis through lipid peroxidation accumulation. Consistent with this, ROS content assessment on liver extracts revealed a similar enhancement in TgHBSP1 and WT treated mice (Fig. 6B). In mouse strains, $48 \mathrm{~h}$ after a single $\mathrm{CCl}_{4}$ injection, liver apoptosis was rarely observed compared to necrosis and neither Desmin transcripts nor $\alpha$-SMA protein expression were upregulated, suggesting that HSCs were not yet activated (Fig. S9). Taken together, these results did not support a direct impact of HBSP expression on $\mathrm{CCl}_{4}$ hepatocyte toxicity as an explanation for the reduced susceptibility of TgHBSP1 mice to liver damage in the chronic exposure model.

Instead we hypothesised that HBSP expression directly downregulated hepatocyte chemokine content and thus monocyte/macrophage recruitment, accounting for the relative resistance 


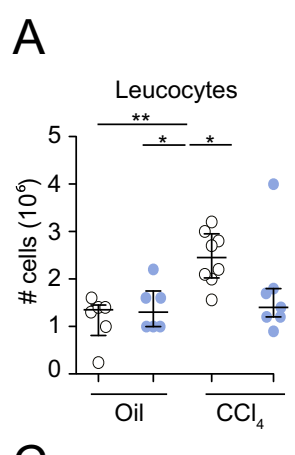

C

CD49b+ NK cells

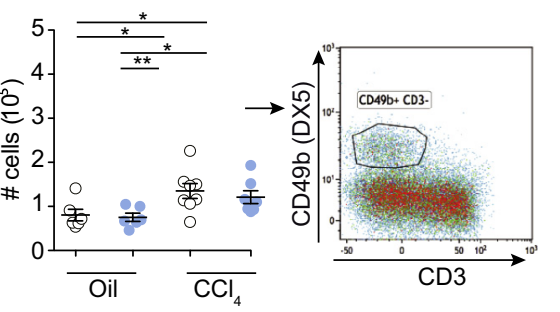

$\mathrm{E}$
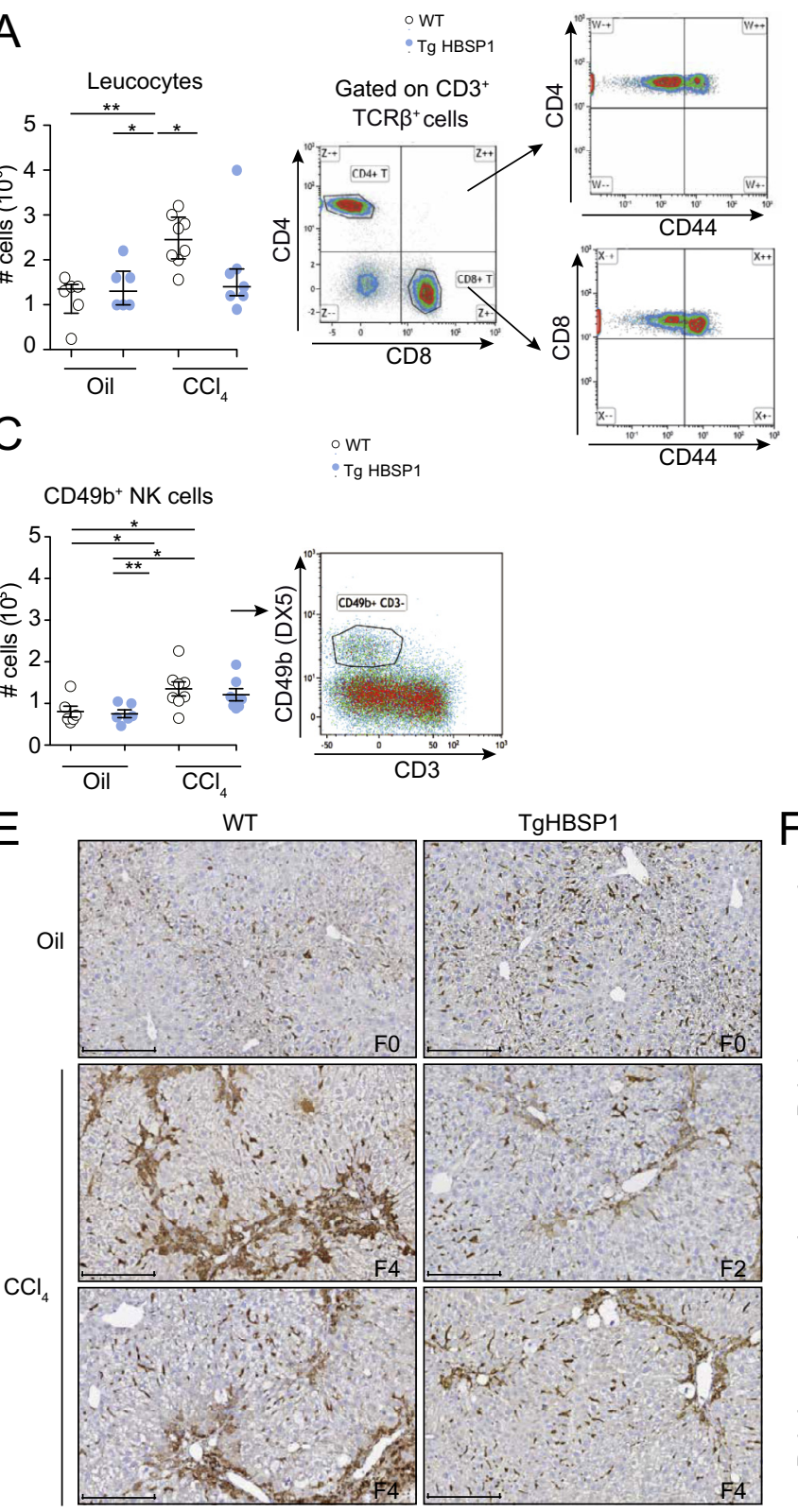

CD4 ${ }^{+} \mathrm{T}$ cells $\quad \mathrm{CD}^{+}{ }^{+} \mathrm{CD} 44^{\text {hi }} \mathrm{T}$ cells $\quad \mathrm{CD}^{+} \mathrm{T}$ cells $\quad \mathrm{CD}^{+} \mathrm{CD} 44^{\mathrm{hi}} \mathrm{T}$ cells

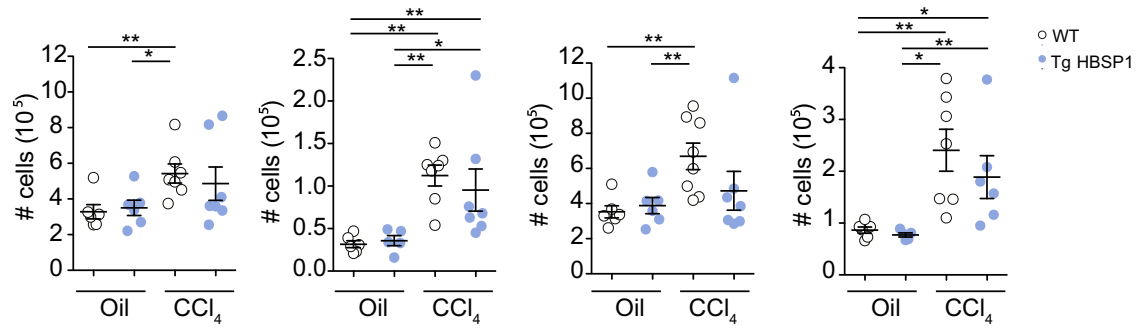

D Monocytes/macrophages $\left(\mathrm{F} 4 / 80^{+} \mathrm{CD} 11 \mathrm{~b}^{+}\right)$
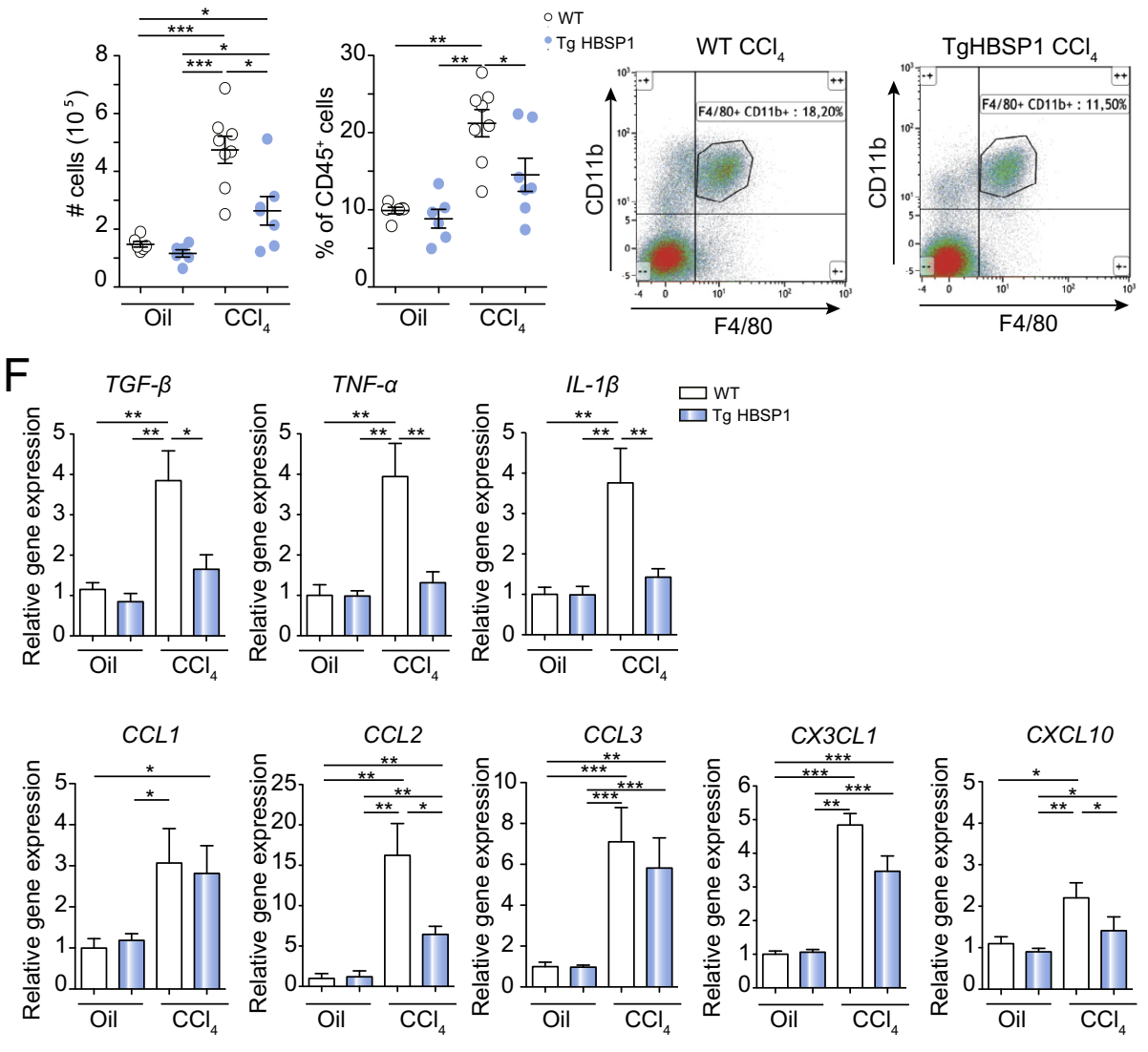

Fig. 5. HBSP expression reduces intrahepatic monocytes/macrophages infiltrate. WT and TgHBSP1 mice were treated for 10 weeks with oil or $\mathrm{CCl}_{4}$. Intrahepatic leucocytes were isolated and analysed by flow cytometry. (A) Intrahepatic leucocyte cells number (left) and representative gating of $\mathrm{CD} 4^{+}$and $\mathrm{CD} 8^{+} \mathrm{T}$ cells (right). (B) $\mathrm{CD} 4^{+} \mathrm{T}\left(7-\mathrm{AAD}^{-}, \mathrm{CD} 3^{+}, \mathrm{TCR}^{+}, \mathrm{CD} 4^{+}\right)$and $\mathrm{CD} 44^{\text {hi }}$ effector/memory $\mathrm{CD} 4^{+} \mathrm{T}$ cells number. CD8 ${ }^{+}$ $\mathrm{T}\left(7-\mathrm{AAD}^{-}, \mathrm{CD}^{+}, \mathrm{TCR}^{+}, \mathrm{CD}^{+}\right)$and $\mathrm{CD} 44^{\text {hi }}$ effector/memory $\mathrm{CD}^{+} \mathrm{T}$ cells number (left). (C) NK (7-AAD ${ }^{-}, \mathrm{CD}^{2} \mathrm{bb}^{+}, \mathrm{CD}^{-}$) cells number and representative gating. (D) Intrahepatic monocytes/macrophage cells

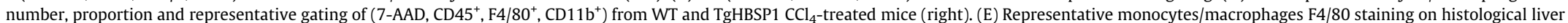
section (bar $250 \mu \mathrm{m}$ ). (F) Cytokines (upper panel) and chemokines (lower panel) mRNA expression in the liver. Each dot represents a mouse; experiments performed on 10 weeks oil-WT ( $n=6$ ). oil-TgHBSP1 $(\mathrm{n}=6), \mathrm{CCl}_{4}$-WT $(\mathrm{n}=8)$ and $\mathrm{CCl}_{4}$-TgHBSP1 $(\mathrm{n}=8)$ treated mice. Mann-Withney U-tests: ${ }^{*} p<0.05,{ }^{* *} p<0.01$ and ${ }^{* * *} p<0.001$. 


\section{Research Article}

A
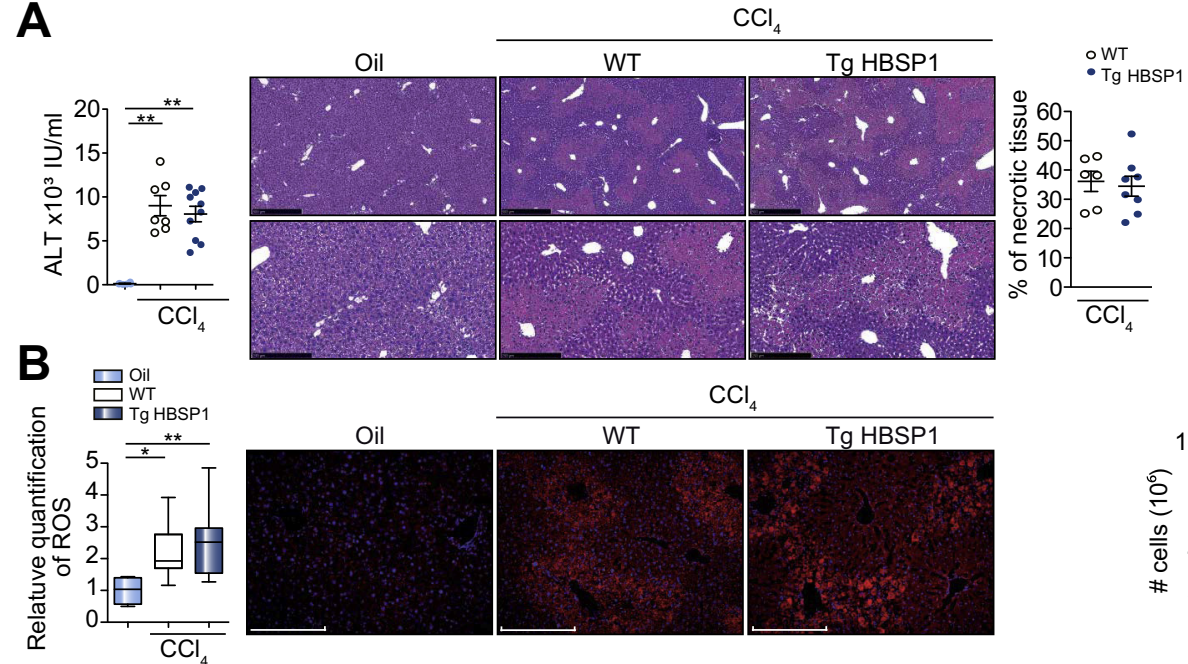

C

C Monocytes/macrophages

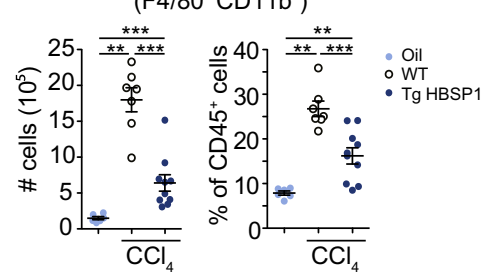
$\left(\mathrm{F} 4 / 80^{+} \mathrm{CD} 11 \mathrm{~b}^{+}\right)$

Ly6Chi CCR2

Leucocytes Monocytes/macrophages
$\mathrm{CCl}_{4}$

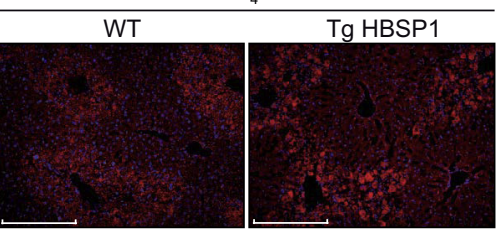

$\mathbf{F}$

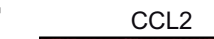

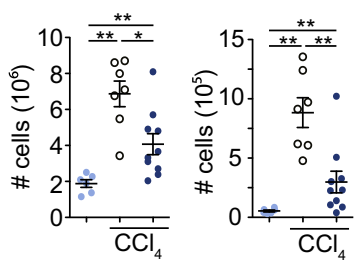

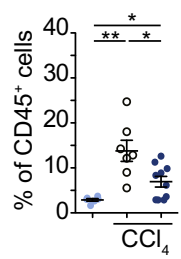

CK18
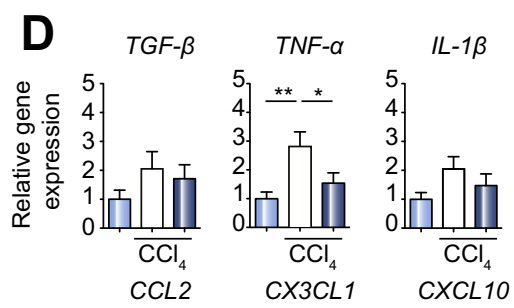

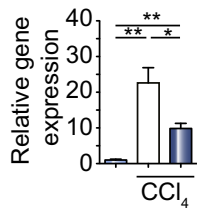
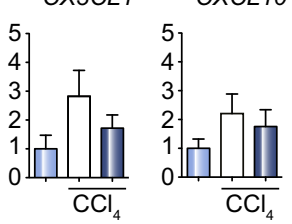
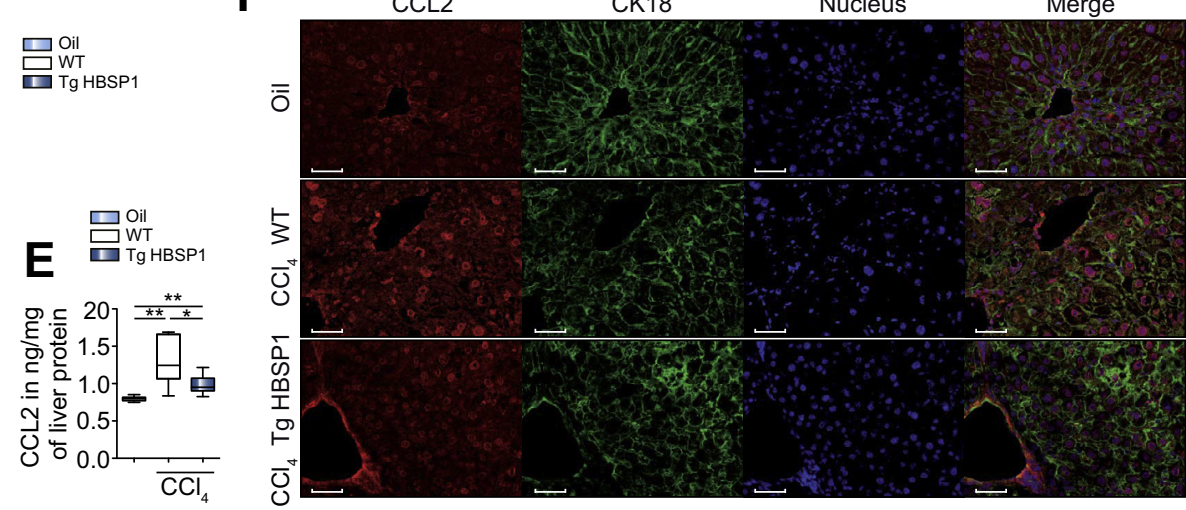

Fig. 6. HBSP has no impact on $\mathrm{CCl}_{4}$-induced hepatocyte acute damage but decreases intrahepatic monocyte/macrophage recruitment and CCL2 expression. WT and TgHBSP1 mice treated with a single injection of oil or $\mathrm{CCl}_{4}$. (A) Sera ALT and liver necrotic tissue quantification on H\&E stained histological section, representative H\&E staining are presented (upper: bar $500 \mu \mathrm{m}$; lower: bar $250 \mu \mathrm{m}$ ). (B) ROS staining on liver frozen section (left, bar $100 \mu \mathrm{m}$ ) and ROS content quantification in liver extract with H2-DCFDA probe (right). (C) Intrahepatic cells number (left) and proportion of monocytes/macrophages (middle; 7-AAD, CD45 ${ }^{+}$, F4/80 ${ }^{+}$, CD11 $\mathrm{b}^{+}$) and proinflammatory Ly6C $\mathrm{C}^{\text {hi }} \mathrm{CCR} 2^{+}$subpopulation (right). (D) Liver cytokines and chemokines mRNA expression. (E) CCL2 quantification in liver protein extract. (F) CCL2 and CK18 immunofluorescence staining on liver sections, nucleus were labelled with Hoescht (bar $50 \mu \mathrm{m})$. Each dot represents a mouse; experiments were performed on oil $(\mathrm{n}=6$ ), $\mathrm{CCl}_{4}$-WT $(\mathrm{n}=7)$ and $\mathrm{CCl}_{4}$-TgHBSP1 $(\mathrm{n}=10)$ single injected mice. Mann-WithneyU-tests: ${ }^{*} p<0.05,{ }^{* *} p<0.01$ and ${ }^{* * *} p<0.001$.

to liver fibrosis in TgHBSP1 treated mice. Therefore, monocyte/macrophage recruitment was investigated by flow-cytometry in the acute $\mathrm{CCl}_{4}$ hepatitis model. As previously observed during chronic exposure, the influx of intrahepatic leucocytes and monocytes/macrophages was significantly reduced in HBSP-expressing mice compared to WT-mice with acute liver injury (Fig. 6C). The monocytes/macrophages that decreased in TgHBSP1 mice included the inflammatory Ly6 $\mathrm{C}^{\text {hi }} \mathrm{CCR}^{+}$subpopulation (Fig. 6C right panel: $\mathrm{CCl}_{4}-\mathrm{WT}$ vs. $\mathrm{CCl}_{4}$-TgHBSP1: $8.8 \pm 0.1 \times 10^{5}$ vs. $2.9 \pm 0.9 \times 10^{5}$ cells, $p=0.003$ and $13.8 \pm 2.3 \%$ vs. $6.9 \pm 1.1 \%$ of CD $45^{+}$cells, $p=0.01$, respectively), recruited through a CCL2dependent mechanism during $\mathrm{CCl}_{4}$ treatment. ${ }^{26}$ The diminished recruitment of monocytes/macrophages in TgHBSP1 acute liver damage was only coupled to a decrease in CCL2 transcripts (Fig. 6D) and to a downregulation of CCL2 protein in the liver (Fig. 6E). Reduced infiltration of monocytes/macrophages, known to be a major source of TNF- $\alpha,{ }^{23}$ might also account for the decrease of TNF- $\alpha$ expression observed. The hepatic cell types producing CCL2 in the acute hepatitis model were further explored by immunofluorescence. CCL2 staining revealed a high signal around blood vessels and unexpectedly hepatocytes (counterstained by cytokeratin 18) were also clearly positive for CCL2 (Fig. 6F).

These data suggested that HBSP expression impacted on liver monocyte/macrophage recruitment through a downregulation of hepatocyte CCL2 expression upon acute liver injury.

\section{HBSP modulates CCL2 expression in hepatocytes}

Our results suggested that CCL2 production by hepatocytes contributes to the recruitment of monocytes/macrophages and consequently to liver damage. Next, we investigated the ability of HBSP to control the expression of CCL2. In line with our previous results, ${ }^{15}$ we showed that p65 (RelA) phosphorylation was impaired in the liver of TgHBSP1 compared to WT mice challenged for 10 weeks with $\mathrm{CCl}_{4}$ (Fig. 7A). This result suggested an impact of NF- $\kappa B$ activation on CCL2 expression. Then, we observed a reduced level of $\mathrm{I} \kappa \mathrm{B} \alpha$ phosphorylation in HeLa 
A

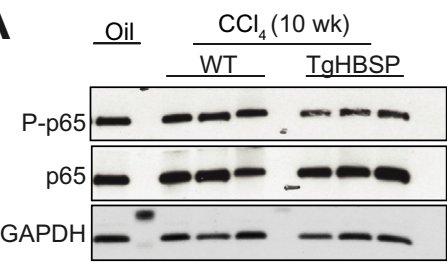

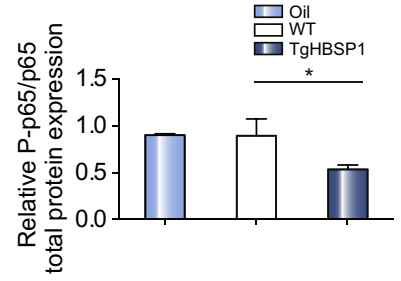

B P-IkBa $\lcm{0 \mathrm{~min} \quad 5 \mathrm{~min} \quad 15 \mathrm{~min}}$ Total IkBa $\ldots \ldots$

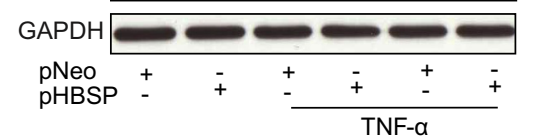

C

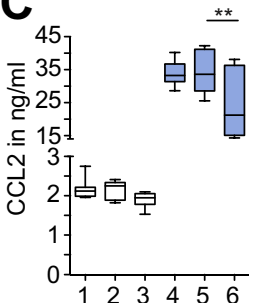

$\mathrm{pNeO}-+-++$

pHBSP - + + - +
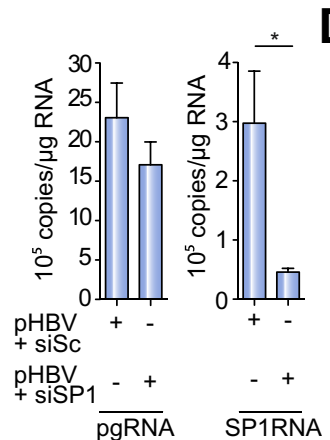

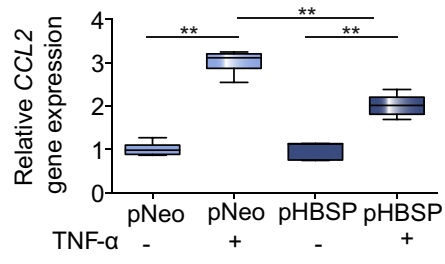

D

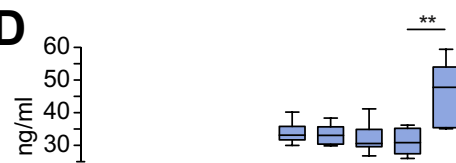

$30-1$

ๆ ${ }^{3}$ 响皇

$\circlearrowleft$

01

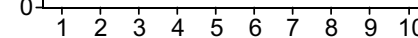

siSc - + - + - + - + -

siSP1 - - + - + - - + - +

$\overline{\mathrm{pNeo}} \overline{\mathrm{pHBV}} \overline{\mathrm{pNeo}} \overline{\mathrm{pHBV}}$
JOURNAL OF HEPATOLOGY

E
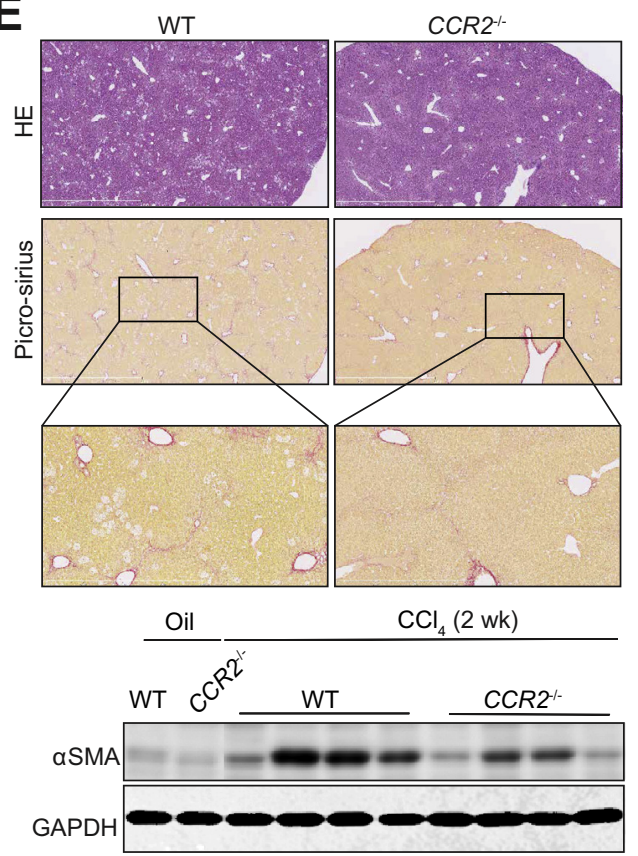

Fig. 7. Association between SP1RNA, HBSP and CCL2 expression in vitro. (A, left panel) Western blot detection of p65 (RelA) total and its phosphorylated form (P-p65) on Ser536 in liver of TgHBSP and control mice treated by vehicle or $\mathrm{CCl}_{4}$ during 10 weeks. (A, right panel) Quantification of P-p65 related expression in liver of TgHBSP and

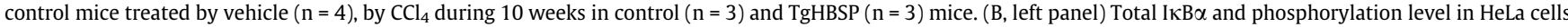
transfected with pNeo or pHBSP plasmids and treated with TNF- $\alpha(25 \mathrm{ng} / \mathrm{ml}$ ) for $0,5,15 \mathrm{~min}$. (B, right panel) Relative CCL2 mRNA quantification (normalized with GAPDH)

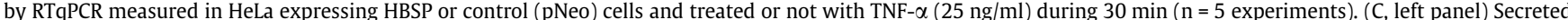
CCL2 protein quantification by HepaRG cells (stimulated or not with $50 \mathrm{ng} / \mathrm{ml}$ TNF- $\alpha$ ) expressing pNeo (control) or pHBSP plasmid ( $\mathrm{n}=7$ experiments). (C, middle panel) HBV pgRNA and SP1RNA quantification from HepaRG cells co-transfected with pHBV plasmid and scramble (siSc) or SP1-siRNA (siSP1) ( $\mathrm{n}=7$ experiments). (D) Secreted CCL2 protein quantification by HepaRG cells (stimulated or not with TNF- $\alpha$ ) expressing pNeo or pHBV plasmid with siSc or siSP1-siRNAs ( $\mathrm{n}=6$ experiments). (E, upper left panel) Representative H\&E and Picro-Sirius red stained histological liver section (bar $2 \mathrm{~mm}$ ) and (E lower left panel) focus of Picro-Sirius red stained (bar $800 \mu \mathrm{m}$ ) of WT and $C C R 2^{-I-}$ mice treated for two weeks with $\mathrm{CCl}_{4}-\mathrm{WT}(\mathrm{n}=)$ and $\mathrm{CCl}_{4}$. (E right panel) Fibrosis-related $\alpha$-SMA protein expression in the liver of WT and $C C R 2^{-I-}$ mice treated for 2 weeks with oil $(\mathrm{n}=2)$ or $\mathrm{CCl}_{4}$ (WT with $\mathrm{n}=4$ out of 5 and $C C R 2^{-1-}$ with $\mathrm{n}=4$ out of 5 ). Mann-Withney $\mathrm{U}$-tests: ${ }^{*} p<0.05$ and ${ }^{* *} p<0.01$.

expressing HBSP cells five minutes after TNF- $\alpha$ treatment (Fig. 7B, left panel), together with a significant reduction of CCL2 transcription level compared to control cells 30 min post-treatment with TNF- $\alpha$ (Fig. 7B, right panel). A significant decrease of CCL2 secretion was also displayed in the supernatant of HepaRG expressing HBSP cells treated by TNF- $\alpha$ (Fig. 7C left panel; lanes 6 vs. 5 , respectively: $24.9 \pm 3.7$ vs. $33.7 \pm 2.3 \mathrm{ng} / \mathrm{ml} ; p=0.008$ ). To further explore CCL2 modulation by HBSP in the context of the whole HBV genome, a siRNA targeting the SP1RNA encoding HBSP was designed. In HBV-transfected HepaRG, siSP1RNA efficiently knocked down SP1RNA (decrease compared to scramble siRNA) without cross-reactivity on pgRNA expression (Fig. 7C middle panel). Upon TNF- $\alpha$ stimulation, CCL2 secretion was significantly higher in HepaRG cells in which SP1RNA had been knocked down than in those transfected with a scramble siRNA (Fig. 7D, lanes 10 vs. 9: $46.3 \pm 4.0$ vs. $31.1 \pm 1.6 \mathrm{ng} / \mathrm{ml}, p=0.008$ ).

To assess whether the reduction of CCL2 expression, through $\mathrm{NF}-\kappa \mathrm{B}$, in HBSP expressing cells may account for the weaker liver fibrogenesis observed in TgHBSP, CCR2 invalidated $\left(C C R 2^{-1-}\right)$ $(\mathrm{n}=5)$ and control $(\mathrm{n}=5)$ mice were treated with $\mathrm{CCl}_{4}$. After two weeks of treatment, picro-sirius staining and Western blot analysis of $\alpha$-SMA expression revealed less marked liver fibrosis in $C C R 2^{-1-}$ mice, highlighting the main influence of this chemokine on fibrogenesis (Fig. 7E).

CCL2 expression relies on SP1RNA in liver of HBV chronic infected patients

Several lines of evidence indicate that subjects with CHB have alterations in chemokines that may drive pathogenesis. ${ }^{27,28} \mathrm{How}-$ ever, the contribution of CCL2 recruitment of monocytes/macrophages has not been addressed in this context. Only a few studies have shown no correlation between circulating CCL2 levels and HBV disease stage, but they do not include information on CCL2 hepatic expression. ${ }^{28,29}$ Furthermore, although HBV splicing regulation was previously suggested during liver disease, $^{8-10,30}$ the contribution of splicing factor expression was never considered. Therefore, we investigated splicing factors and CCL2 expression in liver tissue surplus to diagnostic requirements, available from 12 HBV mono-infected treatment-naive 


\section{Research Article}

A

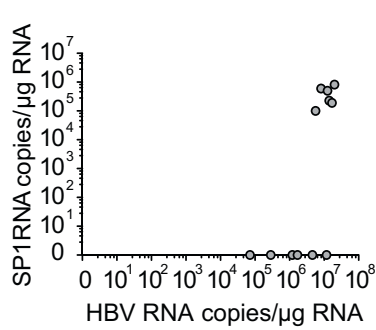

D

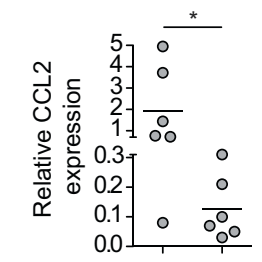

SP1RNA: Und. +

$E$

HBV infected hepatocyte with SP1RNA
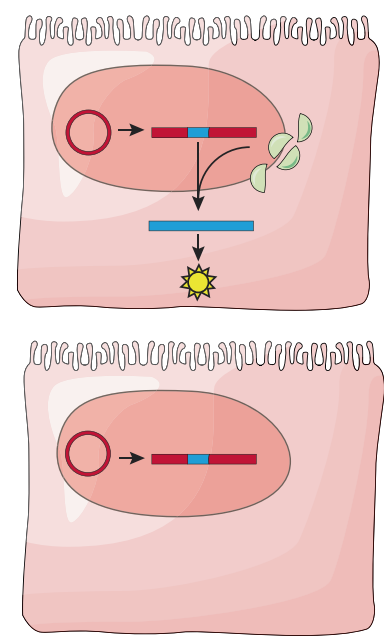

HBV infected hepatocyte without SP1RNA
B

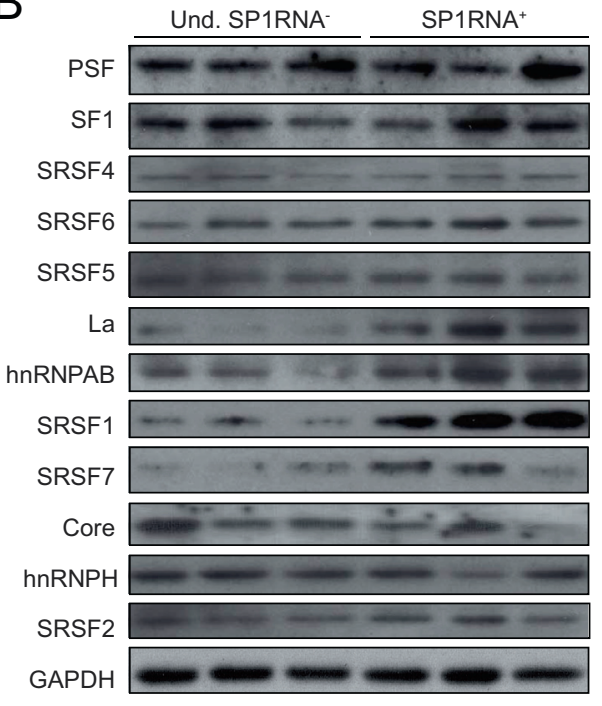

C
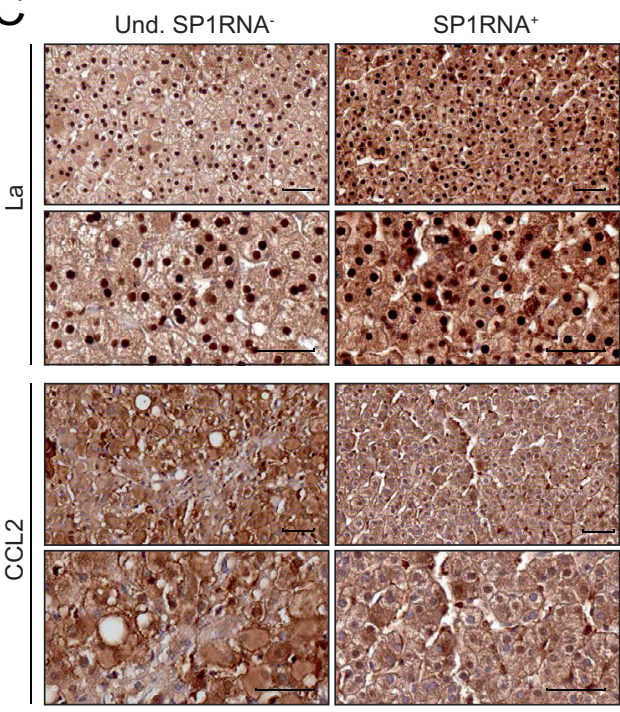

Mild recruitment $\uparrow$

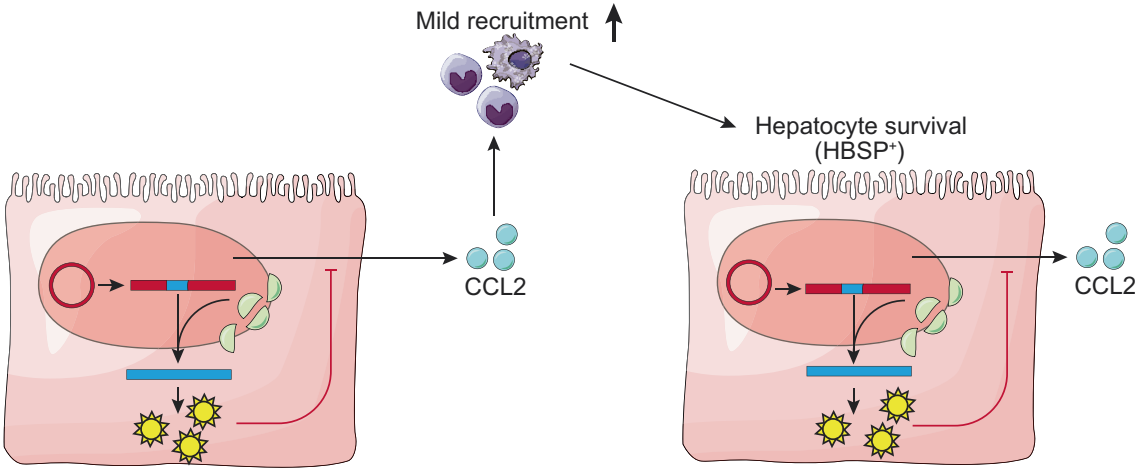

Liver injury

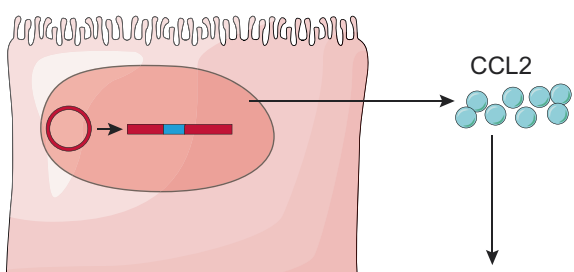

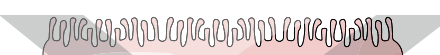

High recruitment $\uparrow \uparrow$
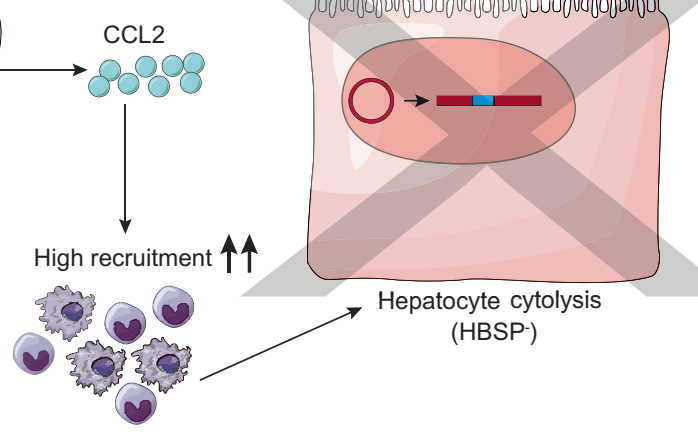

Hepatocyte cytolysis (HBSP-)

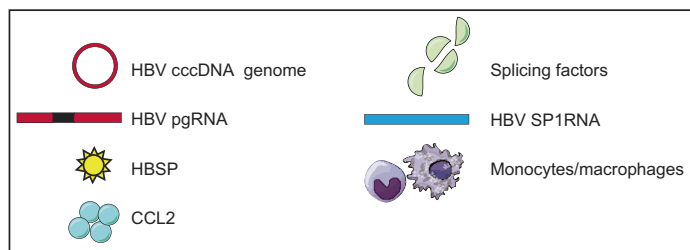

Fig. 8. Association between SP1RNA, CCL2 and trans-regulatory splicing factors in HBV chronic carriers. (A) HBV RNA and SP1RNA quantification in the liver of HBV chronic carriers ( $n=6$ for undetectable (Und.) and $n=6$ for detectable SP1RNA groups). (B) Splicing factors expression in the liver of HBV chronic carriers with undetectable or detectable SP1RNA. (C) La and CCL2 immunochemistry on serial liver section counterstained with hematoxylin (upper and lower bar $50 \mu \mathrm{m}$ ) from chronic HBV carrier with undetectable or detectable SP1RNA. (D) CCL2 mRNA quantification in the liver of HBV chronic carriers with undetectable $(n=6)$ or detectable SP1RNA ( $n=6)$. (E) Schematic model for SP1RNA synthesis and HBSP activity during liver damage. Under liver damage SP1RNA/HBSP expressing hepatocyte through decreasing liver inflammatory microenvironment have a selective advantage leading to the increase of SP1RNA proportion during the course of HBV infection. Mann-Withney U-tests: ${ }^{*} p<0.05$ and ${ }^{* *} p<0.01$.

patients who were either undetectable or positive for HBV SP1RNA (Table S2). All had low-mild liver fibrosis (F0:F1:F2 fibrosis score in SP1RNA ${ }^{+} n=1: 4: 1$, in SP1RNA $\left.{ }^{-} n=0: 6: 0\right)$ with a high level of HBV RNA expression $\left(\mathrm{SP}_{\mathrm{RNA}}{ }^{+}\right.$vs. SP1RNA 


\section{JOURNAL OF HEPATOLOGY}

groups: $1.3 \times 10^{7} \pm 5.3 \times 10^{6}$ vs. $3.3 \times 10^{6} \pm 4.6 \times 10^{6}$ copies of HBV RNA/ $\mu$ g of liver RNA) (Fig. 8A). For $3 / 6$ patients from each group, liver sample size allowed the additional study of the expression of trans-regulatory splicing proteins. Despite exhibiting a similar stage of liver disease, SP1RNA positive liver samples displayed a higher expression of hnRNPAB together with La and SRSF1 splicing factors compared to SP1RNA negative samples (Fig. 8B). These splicing factors were also upregulated in LPS treated HBV transgenic mice. In SP1RNA negative liver samples, La protein expression was mainly observed in the nucleus, whereas in SP1RNA positive liver samples it was at higher levels in both nuclear and cytoplasmic compartments (Fig. 8C), highlighting the shuttling of La protein. ${ }^{31}$ Regarding CCL2 expression on patient liver sections, a differential staining was noticed with an increase in SP1RNA negative hepatocytes (Fig. 7D). The level of intrahepatic CCL2 transcripts was further quantified and SP1RNA positive liver samples displayed a 14-fold lower CCL2 expression compared to SP1RNA negative tissues (Fig. 8D; $0.13 \pm 0.04$ vs. $1.87 \pm 0.80, p=0.01$, respectively).

In conclusion, enhancement of trans-regulatory splicing proteins expression and HBV pgRNA splicing in the liver of patients with CHB was associated with a reduction in CCL2 expression, as previously observed in transgenic mice and in vitro. Our findings support there being a critical role for infected hepatocytes in liver disease through chemokine production, and suggest that a novel feedback loop regulated by HBV counteracts liver pathogenesis.

\section{Discussion}

Alternate splicing regulation of HBV transcripts was first described more than 20 years ago, but its role in HBV disease has remained poorly defined. ${ }^{4,5}$ The proportion of dHBV has been shown to fluctuate considerably in chronic carriers and to increase with the severity of liver pathogenesis. ${ }^{8,9}$ However, the regulation of HBV AS and its impact on liver immunopathogenesis had not been investigated.

To decipher the mechanism of post-transcriptional regulation of HBV pgRNA, hepatic disease was induced in a HBV transgenic mouse model. In contrast to HBV infection models, transgenic mice present the benefit of stable viral genome variability, eliminating any potential interference of HBV cis-regulation on pgRNA/protein interactions. This model is sufficient to decipher the influence of liver damage on post-transcriptional viral regulation, even if the relevance of data obtained on liver pathogenesis is limited, owing to the transgene inducing HBV tolerance and to the constant quantity of viral transcripts (including SP1RNA) and proteins. Interestingly, we showed that chemical liver damage led to a significant increase of HBV AS, suggesting an influence of the microenvironment on the splicing machinery. Indeed, the expression of trans-regulatory splicing proteins interacting with HBV pgRNA was affected by liver injuries in mice, but also in the livers of chronic HBV infected patients (Figs. 3 and 8). Transcriptomic analysis from liver disease samples including hepatocarcinoma have previously suggested a role for such dysregulations of AS factors. ${ }^{32}$ Herein, we reported an impact on HBV AS in vitro, in TgHBV mice and in CHB liver patients. Whilst the modulation of trans-regulatory splicing protein expression differed in liver inflammation and fibrosis in TgHBV treated mice, liver damage triggered the same activation of viral AS. Characterization of molecular pathways ${ }^{33}$ involved in the control of trans-regulatory splicing proteins and consequences on hepatocyte genome expression during liver injury will be important to investigate in further clinical studies.

The main impact of AS regulation is an enhancement of SP1RNA, which encodes HBSP. Unexpectedly, HBSP expression in transgenic mice reduced the liver fibrosis induced by chemical treatment. Our results showed that HBSP expression in the hepatocytes of treated mice downregulated CCL2 expression and consequently reduced the recruitment of monocytes/macrophages. However, an effect on $\mathrm{T}$ cells could not be excluded, considering trends observed in cytometry and cytokine expression data. These tendencies may result either from a domino effect on monocyte/macrophage recruitment, or from an independent direct activity of HBSP on the adaptative immune system. Nevertheless, the direct impact of HBSP on hepatocyte CCL2 expression was confirmed in cells expressing HBSP, as well as in a whole HBV genome context after SP1RNA knockdown. As previously reported, ${ }^{15}$ once activated by inflammation, the NF$\kappa \mathrm{B}$ signaling pathway is partially hijacked by HBSP and as observed in vitro, may account for the downregulation of CCL2 expression. However, TgHBV displayed a similar fibrotic disease to WT mice, despite a non-significant 1.4-fold decrease of CCL2 expression (data not shown) and enhancement of viral AS. In parallel, CCL2-downregulation was found in SP1RNA positive liver patients in HBV chronic carriers with comparable liver injury. These data suggest that HBSP protein has the capacity to antagonize liver fibrogenesis in a dynamic regulation of immune-mediated liver damage, during the course of HBV infection.

Chemokines and their receptors orchestrate the chronology of immune responses during liver injury. Among these chemokines, CCL2 plays a central role in the hepatic recruitment of activated inflammatory monocytes/macrophages expressing Ly6 $\mathrm{C}^{\text {hi }} \mathrm{CCR}^{+}$ markers. ${ }^{23,26,34}$ It was previously suggested that damaged hepatocytes could produce CCL2, ${ }^{35,36}$ but they were considered a minor source compared to activated HSCs and immune cells. ${ }^{35,37}$ Our data highlight the significant contribution of CCL2 produced by hepatocytes in liver damage, since CCL2 downregulation in TgHBSP mice had a direct impact on liver pathogenesis. Therefore, reduced monocyte/macrophage infiltrates may account for the differential expression of cytokines and for the recruitment of other immune cells in 10 -week $\mathrm{CCl}_{4-}$ treated mice, which also seemed partially affected, compared to control mice. Nevertheless, the main role of CCL2 downregulation was supported by the data obtained from the single $\mathrm{CCl}_{4}$ injection in TgHBSP mice, as well as the similar impairment of liver fibrosis observed in $C C R 2^{-I-}$ treated mice. Although altered immune composition at baseline may limit conclusions for the last model. The influence of monocytes/macrophages during HBV pathogenesis has been poorly explored, even if the modulation of non-cytolytic antiviral activity via their cytokine secretion was reported. ${ }^{38-40}$ Additionally, monocytes/macrophages could participate in HBV specific adaptive immunity through the formation of intrahepatic myeloid-cell aggregates, enabling local $\mathrm{CD}^{+} \mathrm{T}$ cell expansion (iMATEs). ${ }^{41,42}$ Thus, by countering monocyte/macrophage recruitment, HBSP might support the maintenance of a tolerogenic environment and favour immune escape. ${ }^{43}$ Furthermore, the relationship between CCL2 and human HCC survival emphasizes the clinical observation of HBV splicing enhancement prior to development of HCC and hints at the role of HBSP in liver disease progression. ${ }^{44}$ 


\section{Research Article}

Previous clinical data have reported a link between SP1RNA related increases in HBV defective circulating particles and viral liver disease severity..$^{8-10}$ Consequently, our present study suggests a new feedback loop involving HBV AS to counteract liver injury. As proposed in Fig. 8E, the hepatic microenvironment, altered by liver damage, may contribute to enhance splicing factors involved in HBV SP1RNA production, and thus HBSP expression. Hepatocytes expressing HBSP exhibit reduced CCL2 secretion and consequently attenuated monocyte/macrophage recruitment, thereby constraining inflammation. Although speculative at this stage, it is possible that hepatocytes expressing HBV SP1RNA are preferentially maintained by inhibition of local antiviral immunity, constituting a novel mechanism for viral persistence during chronic liver injury. It remains unclear whether efficient viral suppression by antiviral therapy is possible for the management of HBV infection. Eradication of intracellular virus remains challenging. However, CCL2 targeted immunotherapy, in combination with nucleoside analog, should contribute to an efficient HBV cure through disruption of the immune tolerance established during viral infection.

\section{Financial support}

This work was supported by grants from Institut National de la Sante et de la Recherche Medicale (Inserm) - France, Universite Pierre et Marie Curie (UPMC) - France, Agence National de la Recherche sur le Sida et les Hepatites (ANRS) - France ( ${ }^{\circ}$ N14015DR) and PHC-Tassili (11MDU826). MD was supported by ANRS (grant ASA14013DRA). YM was supported by French Ministry for Higher Education and Research and by the Ligue contre le Cancer (grant $n^{\circ} \mathrm{GB} / \mathrm{MA} / \mathrm{VSP}-10504$ ).

\section{Conflict of interest}

The authors who have taken part in this study declared that they do not have anything to disclose regarding funding or conflict of interest with respect to this manuscript.

Please refer to the accompanying ICMJE disclosure forms for further details.

\section{Authors' contributions}

Conception and design of these experiments MD, YM, DK and PS. Conduction the experiments: MD, YM, BL, HW, AS, FR, VF, JA, IQ CC and PS. Analysis of the data: MD, YM, BL, CG, DS, ML, MM and PS. Provide biological samples: SG, UG, PK, AB, MM and ND. Wrote the paper: MD, MM and PS.

\section{Acknowledgments}

We thank N. Stadler, C. Cordier, B. Kane and F. Marliot for technical assistance; and Drs D. Auboeuf, C. Bourgeois, T. Heise, O. Ann for providing SRSF1 and PSF plasmids. We thank Drs ML. Michel, S. Briechler, H. Strick-Marchand, F. Pagès, D. Scott-Algara, A. Coulomb, J. Pol and T. Capiod for helpful scientific discussion. We thank animal facilities platform from Pitié and Broussais Universities. We thank FACS, proteomic and histological platforms of Broussais institute.

\section{Supplementary data}

Supplementary data associated with this article can be found, in the online version, at http://dx.doi.org/10.1016/j.jhep.2017.05. 025 .

\section{References}

Author names in bold designate shared co-first authorship

[1] Pohl M, Bortfeldt RH, Grutzmann K, et al. Alternative splicing of mutually exclusive exons-a review. Biosystems 2013:114:31-38.

[2] Hernandez-Lopez HR, Graham SV. Alternative splicing in human tumour viruses: a therapeutic target? Biochem J 2012;445:145-156.

[3] Han SP, Tang YH, Smith R. Functional diversity of the hnRNPs: past, present and perspectives. Biochem J 2010;430:379-392.

[4] Susuki T, Masui N, Kajino K, et al. Detection and mapping of spliced RNA from a human hepatoma cell line transfected with the hepatitis B virus genome. Proc Nat Acad Sci USA 1989;86:8422-8426.

[5] Wu H-L, Chen P-J, Tu S-J, et al. Characterization and genetic analysis of alternatively spliced transcripts of hepatitis B virus in infected human liver tissues and transfected Hep G2 cells. JVirol 1991;65:1680-1686.

[6] Seeger C, Mason WS. Molecular biology of hepatitis B virus infection. Virology 2015;479-480C:672-686.

[7] Terre S, Petit MA, Brechot C. Defective hepatitis B virus particles are generated by packaging and reverse transcription of spliced viral RNAs in vivo. J Virol 1991;65:5539-5543.

[8] Bayliss J, Lim L, Thompson AJ, et al. Hepatitis B virus splicing is enhanced prior to development of hepatocellular carcinoma. J Hepatol 2013;59:1022-1028.

[9] Redelsperger F, Lekbaby B, Mandouri Y, et al. Production of hepatitis B defective particles is dependent on liver status. Virology 2012:431:21-28.

[10] Soussan P, Pol J, Garreau F, et al. Expression of defective hepatitis B virus particles derived from singly spliced RNA is related to liver disease. J Infect Dis 2008:198:218-225.

[11] Chen J, Wu M, Wang F, et al. Hepatitis B virus spliced variants are associated with an impaired response to interferon therapy. Sci Rep 2015;5:16459.

[12] Soussan P, Garreau F, Zylberberg H, et al. In vivo expression of a new hepatitis B virus protein encoded by a spliced RNA. J Clin Invest 2000:105:55-60.

[13] Bayard F, Godon O, Nalpas B, et al. T-cell responses to hepatitis B splicegenerated protein of hepatitis B virus and inflammatory cytokines/chemokines in chronic hepatitis B patients. ANRS study: HB EP 02 HBSP-FIBRO. J Viral Hepat 2012;19:872-880.

[14] Chen JY, Chen WN, Jiao BY, et al. Hepatitis B spliced protein (HBSP) promotes the carcinogenic effects of benzo [alpha] pyrene by interacting with microsomal epoxide hydrolase and enhancing its hydrolysis activity. BMC Cancer 2014;14:282.

[15] Pol JG, Lekbaby B, Redelsperger F, et al. Alternative splicing-regulated protein of hepatitis B virus hacks the TNF-alpha-stimulated signaling pathways and limits the extent of liver inflammation. FASEB J 2015;5:1879-1889.

[16] Cheng L, Li F, Bility MT, et al. Modeling hepatitis B virus infection, immunopathology and therapy in mice. Antiviral Res 2015;121:1-8.

[17] Guidotti LG, Matzke B, Schaller H, et al. High-level hepatitis B virus replication in transgenic mice. J Virol 1995;69:6158-6169.

[18] Rodero MP, Poupel L, Loyher PL, et al. Immune surveillance of the lung by migrating tissue monocytes. Elife 2015;4:e07847.

[19] Zhao J, Zhang Z, Luan Y, et al. Pathological functions of interleukin-22 in chronic liver inflammation and fibrosis with hepatitis B virus infection by promoting T helper 17 cell recruitment. Hepatology 2014;59:1331-1342.

[20] Chen Y, Wei H, Sun R, et al. Increased susceptibility to liver injury in hepatitis B virus transgenic mice involves NKG2D-ligand interaction and natural killer cells. Hepatology 2007;46:706-715.

[21] Fu XD, Ares Jr M. Context-dependent control of alternative splicing by RNAbinding proteins. Nat Rev Genet 2014:15:689-701.

[22] Pellicoro A, Ramachandran P, Iredale JP, et al. Liver fibrosis and repair: immune regulation of wound healing in a solid organ. Nat Rev Immunol 2014;14:181-194.

[23] Marra F, Tacke F. Roles for chemokines in liver disease. Gastroenterology 2014;147:577-594 e571. 
[24] Beattie L, Sawtell A, Mann J, et al. Bone marrow-derived and resident liver macrophages display unique transcriptomic signatures but similar biological functions. J Hepatol 2016;65:758-768.

[25] Karlmark KR, Zimmermann HW, Roderburg C, et al. The fractalkine receptor CX(3)CR1 protects against liver fibrosis by controlling differentiation and survival of infiltrating hepatic monocytes. Hepatology 2010;52:1769-1782.

[26] Baeck C, Wei X, Bartneck M, et al. Pharmacological inhibition of the chemokine C-C motif chemokine ligand 2 (monocyte chemoattractant protein 1) accelerates liver fibrosis regression by suppressing $\mathrm{Ly}-6 \mathrm{C}(+)$ macrophage infiltration in mice. Hepatology 2014;59:1060-1072.

[27] Ren YY, Liu YZ, Ding YP, et al. Immune characteristics of different immune phases in natural course of chronic HBV infection. Hepatogastroenterology 2013;60:789-795.

[28] Tan AT, Koh S, Goh W, et al. A longitudinal analysis of innate and adaptive immune profile during hepatic flares in chronic hepatitis B. J Hepatol 2010;52:330-339.

[29] Lian JQ, Yang XF, Zhao RR, et al. Expression profiles of circulating cytokines, chemokines and immune cells in patients with hepatitis B virus infection. Hepat Mon 2014;14:e18892.

[30] Soussan P, Tuveri R, Nalpas B, et al. The expression of hepatitis B spliced protein (HBSP) encoded by a spliced hepatitis B virus RNA is associated with viral replication and liver fibrosis. J Hepatol 2003;38:343-348.

[31] Bayfield MA, Yang R, Maraia RJ. Conserved and divergent features of the structure and function of La and La-related proteins (LARPs). Biochim Biophys Acta 2010;1799:365-378.

[32] Chettouh H, Fartoux L, Aoudjehane L, et al. Mitogenic insulin receptor-A is overexpressed in human hepatocellular carcinoma due to EGFR-mediated dysregulation of RNA splicing factors. Cancer Res 2013;73:3974-3986.

[33] Mallinjoud P, Villemin JP, Mortada H, et al. Endothelial, epithelial, and fibroblast cells exhibit specific splicing programs independently of their tissue of origin. Genome Res 2014;24:511-521.

\section{JOURNAL OF HEPATOLOGY}

[34] Dambach DM, Watson LM, Gray KR, et al. Role of CCR2 in macrophage migration into the liver during acetaminophen-induced hepatotoxicity in the mouse. Hepatology 2002;35:1093-1103.

[35] Saiman Y, Friedman SL. The role of chemokines in acute liver injury. Front Physiol 2012;3:213.

[36] Ziraldo C, Vodovotz Y, Namas RA, et al, Central role for MCP-1/CCL2 in injury-induced inflammation revealed by in vitro, in silico, and clinical studies. PLoS One 2013;8:e79804.

[37] Ait-Goughoulte M, Lucifora J, Zoulim F, et al. Innate antiviral immune responses to hepatitis B virus. Viruses 2010;2:1394-1410.

[38] Boltjes A, Movita D, Boonstra A, et al. The role of Kupffer cells in hepatitis B and hepatitis C virus infections. J Hepatol 2014;61:660-671.

[39] Boltjes A, van Montfoort N, Biesta PJ, et al. Kupffer cells interact with hepatitis B surface antigen in vivo and in vitro, leading to proinflammatory cytokine production and natural killer cell function. J Infect Dis 2014;211:1268-1278.

[40] Hosel M, Quasdorff M, Wiegmann K, et al. Not interferon, but interleukin-6 controls early gene expression in hepatitis B virus infection. Hepatology 2009;50:1773-1782.

[41] Huang LR, Wohlleber D, Reisinger F, et al. Intrahepatic myeloid-cell aggregates enable local proliferation of CD8(+) T cells and successful immunotherapy against chronic viral liver infection. Nat Immuno 2013:14:574-583.

[42] Nakamoto N, Kanai T. Role of toll-like receptors in immune activation and tolerance in the liver. Front Immunol 2014;5:221.

[43] Heymann F, Peusquens J, Ludwig-Portugall I, et al. Liver inflammation abrogates immunological tolerance induced by Kupffer cells. Hepatology 2015;62:279-291.

[44] Li X, Yao W, Yuan Y, et al. Targeting of tumour-infiltrating macrophages via CCL2/CCR2 signalling as a therapeutic strategy against hepatocellular carcinoma. Gut 2015;66:157-167. 